\title{
Prognostic value of microRNAs in colorectal cancer: a meta-analysis
}

This article was published in the following Dove Press journal: Cancer Management and Research

\author{
Song Gaol,* \\ Zhi-Ying Zhao ${ }^{2, *}$ \\ Rong Wu' \\ Yue Zhang ${ }^{3}$ \\ Zhen-Yong Zhang'
}

'Second Department of Clinical Oncology, Shengjing Hospital of China Medical University, ${ }^{2} \mathrm{School}$ of Computer Science and Engineering, Northeastern University, Shenyang,

${ }^{3}$ First Clinical Medical College, Shandong University of Traditional

Chinese Medicine, Jinan, China

*These authors contributed equally to this work

\section{Correspondence: Yue Zhang}

First Clinical Medical College, Shandong University of Traditional Chinese

Medicine, 16369 Jingshi Road, Lixia, Jinan,

Shandong 2500I4, China

$\mathrm{Tel}+8653168616426$

Fax +86 53। 82602948

Email zhangyue08II@hotmail.com

Zhen-Yong Zhang

Second Department of Clinical Oncology,

Shengjing Hospital of China Medical

University, 39 Huaxiang Road, Tiexi,

Shenyang, Liaoning I I0022, China

Tel +86 I89 40257577

Fax +862423842568

Email zhangzy@sj-hospital.org
Background: Numerous studies have shown that miRNA levels are closely related to the survival time of patients with colon, rectal, or colorectal cancer (CRC). However, the outcomes of different investigations have been inconsistent. Accordingly, a meta-analysis was conducted to study associations among the three types of cancers.

Materials and methods: Studies published in English that estimated the expression levels of miRNAs with survival curves in CRC were identified until May 20, 2017 by online searches in PubMed, Embase, Web of Science, and the Cochrane Library by two independent authors. Pooled HRs with $95 \%$ CIs were used to estimate the correlation between miRNA expression and overall survival.

Results: A total of 63 relevant articles regarding 13 different miRNAs, with 10,254 patients were ultimately included. CRC patients with high expression of blood miR141 (HR 2.52, 95\% CI 1.68-3.77), tissue miR21 (HR 1.31, 95\% CI 1.12-1.53), miR181a (HR 1.52, 95\% CI 1.26-1.83), or miR224 (HR 2.12, 95\% CI 1.04-4.34), or low expression of tissue miR126 (HR $1.55,95 \%$ CI 1.24-1.93) had significantly poor overall survival $(P<0.05)$.

Conclusion: In general, blood miR141 and tissue miR21, miR181a, miR224, and miR126 had significant prognostic value. Among these, blood miR141 and tissue miR224 were strong biomarkers of prognosis for CRC.

Keywords: microRNA, colorectal cancer, prognosis, meta-analysis

\section{Introduction}

Numerous researchers have studied the associations between miRNA expression and the survival outcomes of colorectal cancer (CRC) patients. ${ }^{1-258} \mathrm{CRC}$ has a $10 \%$ cancer incidence and mortality worldwide, ${ }^{259}$ and thus, it is one of the most serious diseases threatening human health. Despite great success in the treatment of CRC, the prognosis of CRC patients is still poor. Therefore, it is fundamental for the diagnosis, treatment, and prognosis of CRC patients to understand its emphasized molecular origin. ${ }^{260}$ Despite a comprehensive study about the mechanisms of $\mathrm{CRC}$, there are still some challenges that require recognizing prognostic biomarkers with minimal invasion and sensitivity. Accordingly, it is of vital significance to improve the survival rate of CRC patients, utilizing rapid and reliable tumor-prognosis biomarkers.

miRNAs, small noncoding RNA gene products of approximately 22 nucleotides, are found in various types of organisms. They account for $2 \%-5 \%$ of the entire genome, number about 1,000 , and regulate the expression of $\geq 20 \%$ of human genes. ${ }^{261}$ In addition, they play crucial roles in regulating the translation and degradation of mRNAs via 
base pairing to partially complementary sites, predominantly in the 3'-untranslated areas of mRNAs. ${ }^{262-264}$

In the study of CRC, a large number of articles have covered the fact that miRNAs are closely related to the survival time of patients. ${ }^{1-258}$ There were relatively small samples in these papers, and the present work aims to estimate the most accurate prognostic value between miRNA level and survival outcome of CRC patients, better to comprehend the miRNAs with prognostic pertinence that are potential candidates for clinical verification in the future.

\section{Materials and methods}

\section{Search strategy}

We used four online databases - PubMed, Embase, Web of Science, and the Cochrane Library - to find pertinent literature published until May 20, 2017. The combination term "miR and colorectal cancer" was employed for the literature search. Two authors (S Gao and ZY Zhao) independently performed this comprehensive online search.

\section{Inclusion criteria}

Articles qualified if they satisfied the following criteria: patients with colon/rectal cancer or CRC; miRNA levels in tissue, plasma, or serum and survival results were measured; at least one survival curve was measured of overall survival (OS), cause-specific survival (CSS), disease-free survival (DFS), recurrence-free survival (RFS), progression-free survival (PFS), and metastasis-free survival (MFS), with or without HRs/95\% CIs; and full text published in English.

\section{Exclusion criteria}

Exclusion criteria were experimental studies, reviews, or letters without primary data and retracted papers; frequency of research evaluating prognostic value of miRNAs in tissue of four or less. Only the most comprehensive study was included for this meta-analysis if more than one paper had been published in the same research group.

\section{Quality assessment}

SG and ZY Zhao identified all qualifying studies analyzing the prognostic value of miRNAs in $\mathrm{CRC}$, and $\mathrm{YZ}$ reevaluated uncertain data.

\section{Study selection}

A flow diagram of the study selection process is presented in Figure 1. Our study found 1,843 articles for consideration within this meta-analysis, and 322 articles suitable for assessment of prognostic miRNA signatures in CRC and full-text papers were acquired by evaluating titles and abstracts. On elaborate review of research methodologies, 64 investigations were excluded, the details of which are shown in Figure 1. On the basis of the exclusion criteria, 63 studies were finally included in this meta-analysis.

\section{Study frequency}

The frequency of studies estimating the prognostic value of miRNAs in CRC are shown in Tables 1 (blood) and 2 (tissue), including miRNA name, number of studies estimating prognostic value, and references.

\section{Study characteristics}

Literature with Kaplan-Meier survival curves for CRC are detailed in Table 3. If data were not provided visually and merely as curves, they were extracted from the curves, and estimated HRs with 95\% CIs were subsequently calculated using the method of Tierney et $\mathrm{al}^{265}$ with Engauge Digitizer version 4.1 software. In addition, if outcomes of both univariate and multiple covariates were covered, only the latter was chosen, because of adjustment for confounders.

\section{Statistical analyses}

All analyses were performed utilizing Stata version 13.0 (StataCorp, College Station, TX, USA). Merged HRs were regarded as significant at the $P<0.05$ level if $95 \%$ CIs did not contain the value 1 . Effect values for HRs were regarded as large if $\geq 2$. HRs for OS were regarded as the prime reference standard if OS $P$-values were inconsistent with other survival outcomes with respect to the associated miRNA level. All analyses employed random-effect models instead of fixed-effect models, because there existed differences among the studies, including tissue detected (frozen or formalinfixed, paraffin-embedded), blood (plasma or serum), tumor stage (I-IV), cutoff values, and miRNA-analysis methods. Publication bias was measured by Begg's funnel plot, and a two-tailed $P$-value $<0.05$ was regarded as significant. The trim-and-fill method was performed if publication bias occurred. Sensitivity analysis was employed to weigh how powerful merged HRs were after a single study had been removed. An individual study was suspected of having excess of influence if the point estimation was outside the $95 \%$ CI after removal from the analysis.

\section{Results}

\section{Meta-analysis}

An overview of HRs appraised from comprehensive analysis of all the miRNAs is given in Table 4. Thirteen miRNAs were involved in this meta-analysis: miR21, miR92a, miR106a, miR125b, miR126, miR141, miR143, miR145, miR181a, 


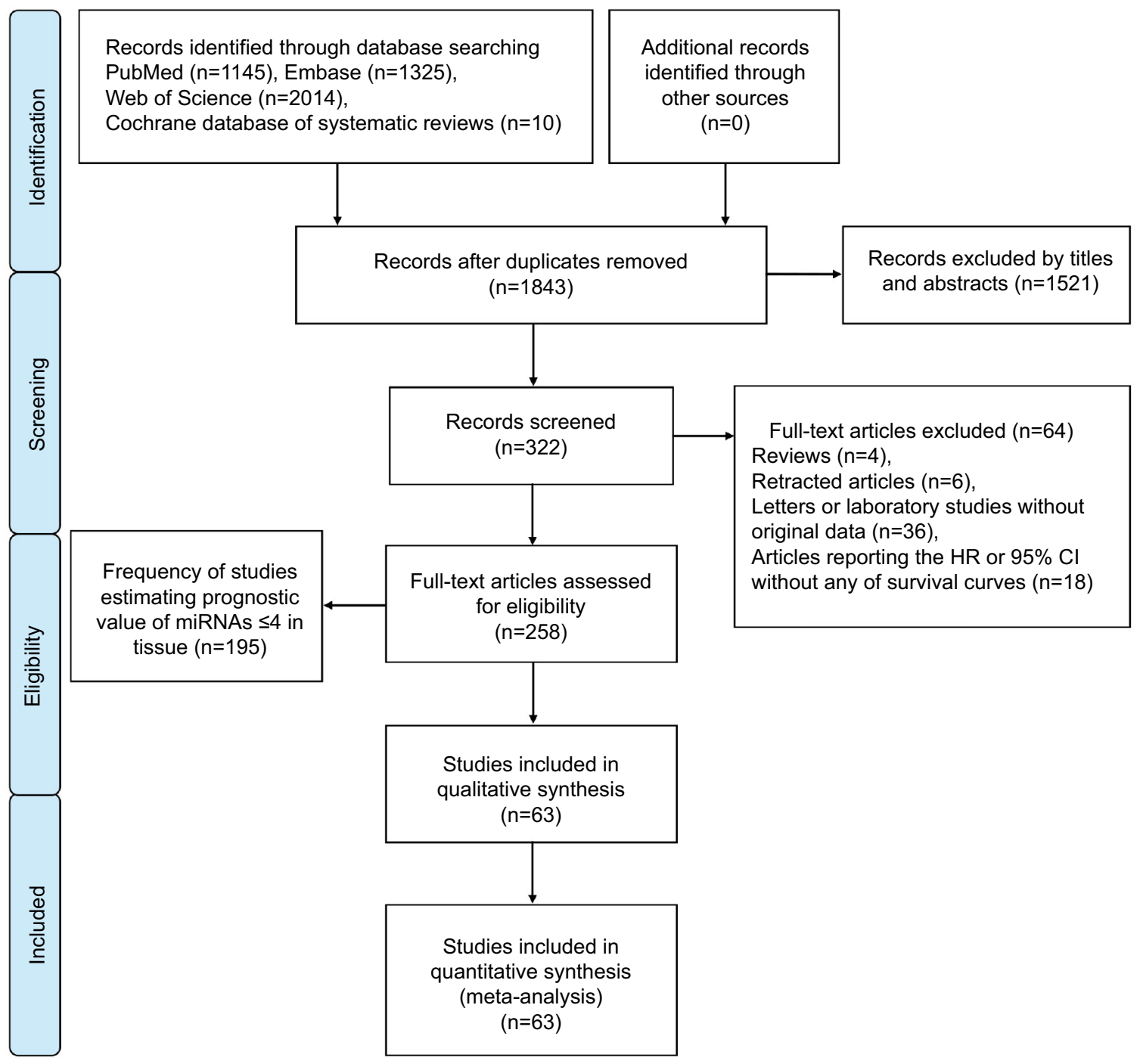

Figure I Flow diagram of literature search and selection.

Table I Frequency of studies estimating prognostic value of blood miRNA expression in colorectal cancer

\begin{tabular}{|c|c|c|c|c|c|c|c|c|}
\hline miR & $\mathbf{n}$ & Reference(s) & miR & $\mathbf{n}$ & Reference(s) & $\mathrm{miR}$ & $\mathbf{n}$ & Reference(s) \\
\hline $15 b$ & I & 1 & 122 & 1 & 16 & 221 & I & 26 \\
\hline $17-3 p$ & 1 & 2 & $124-5 p$ & 1 & 9 & $324-3 p$ & I & 12 \\
\hline $19 a$ & I & 3 & 135 & 1 & 17 & 345 & I & 12 \\
\hline 21 & 4 & $4-7$ & $139-5 p$ & 1 & 18 & 372 & I & 27 \\
\hline $23 b$ & 1 & 8 & $14 \mid$ & 2 & 14,19 & $628-5 p$ & I & 12 \\
\hline $26 a$ & 1 & 9 & 143 & 1 & 12 & $885-5 p$ & I & 28 \\
\hline $29 a$ & 1 & 10 & 155 & I & 20 & $886-3 p$ & I & 12 \\
\hline $29 b$ & I & 11 & 183 & 1 & 21 & 1290 & I & 29 \\
\hline $34 a^{*}$ & I & 12 & 194 & I & 11 & $4772-3 p$ & I & 30 \\
\hline $92 a$ & 2 & 10,13 & $196 b$ & I & 22 & 6826 & I & 17 \\
\hline 96 & 1 & 14 & $200 \mathrm{~b}$ & 2 & 14,16 & 6875 & 1 & 17 \\
\hline 103 & 1 & 15 & $200 c$ & I & 23 & & & \\
\hline $106 a$ & I & 2 & 203 & 2 & 24,25 & & & \\
\hline
\end{tabular}

Note: Highlighted studies were included in the present meta-analysis. 


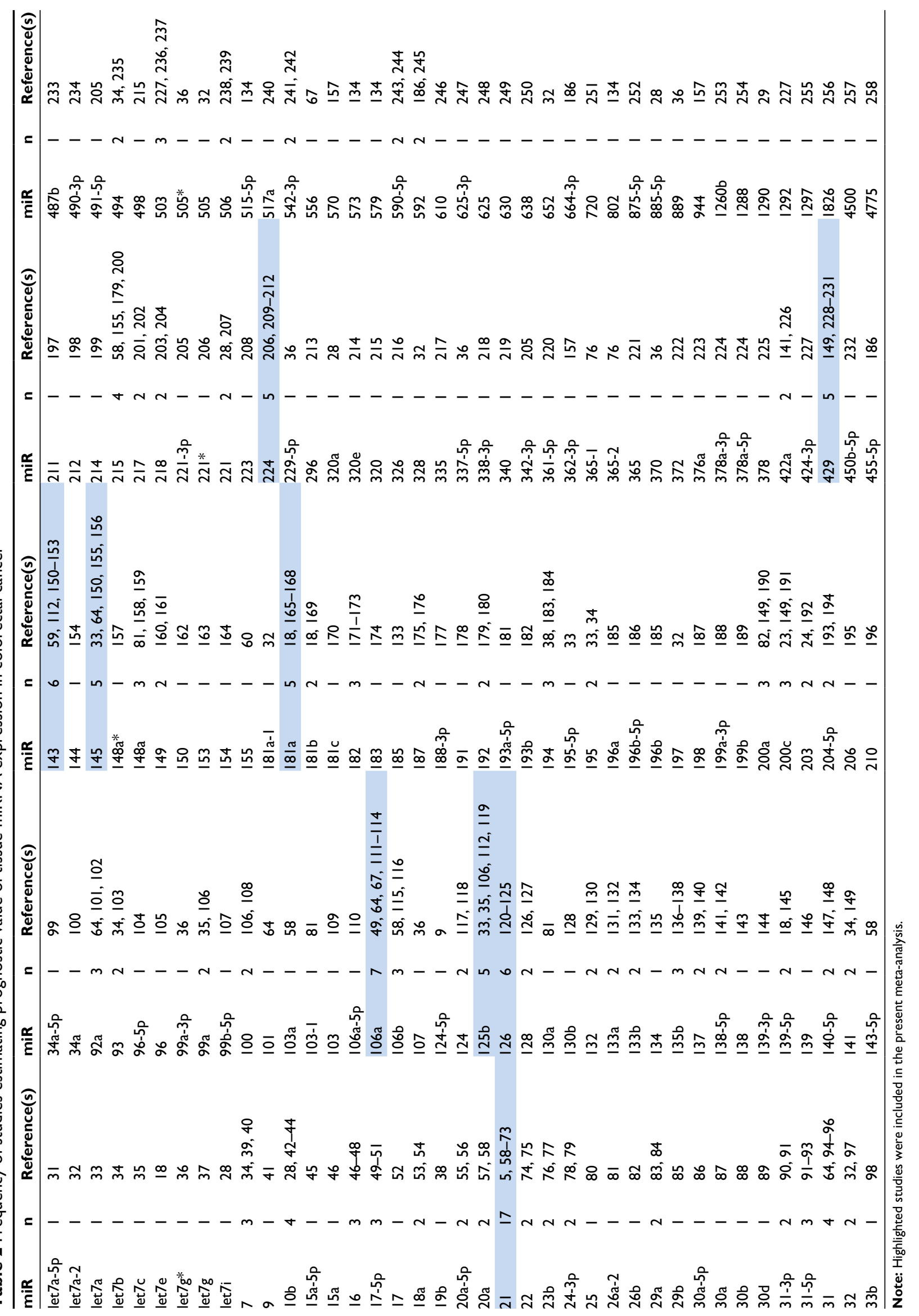




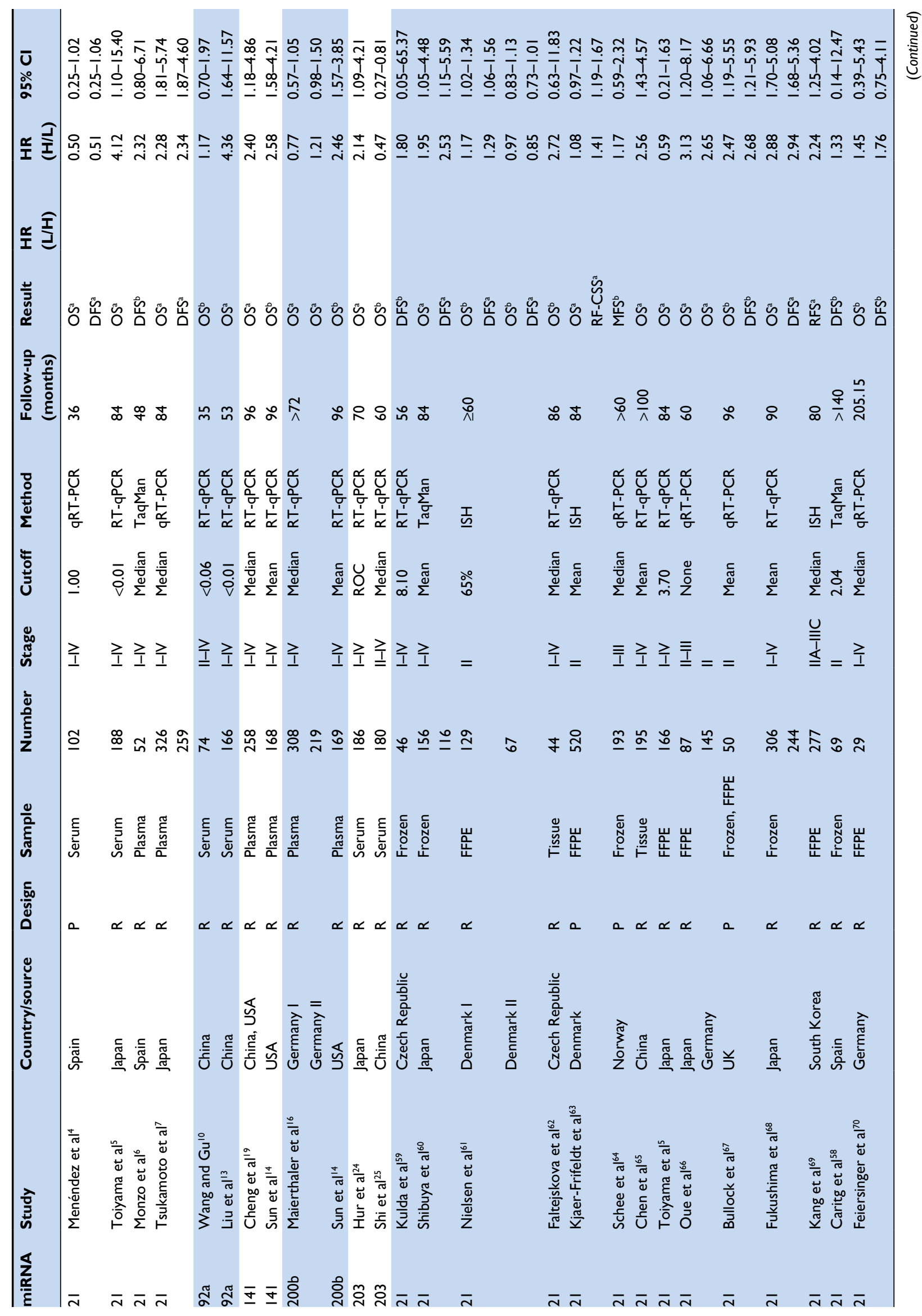




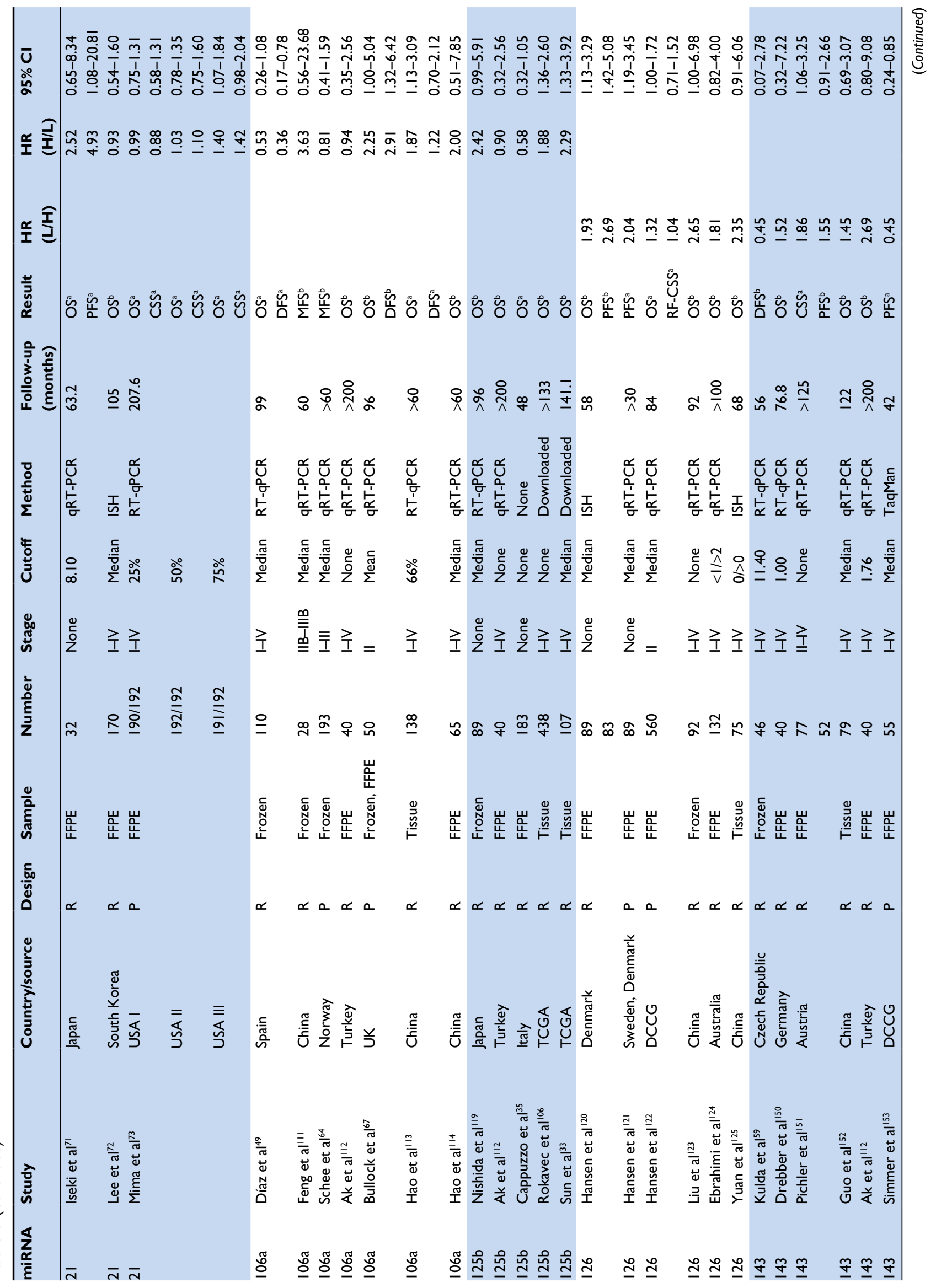




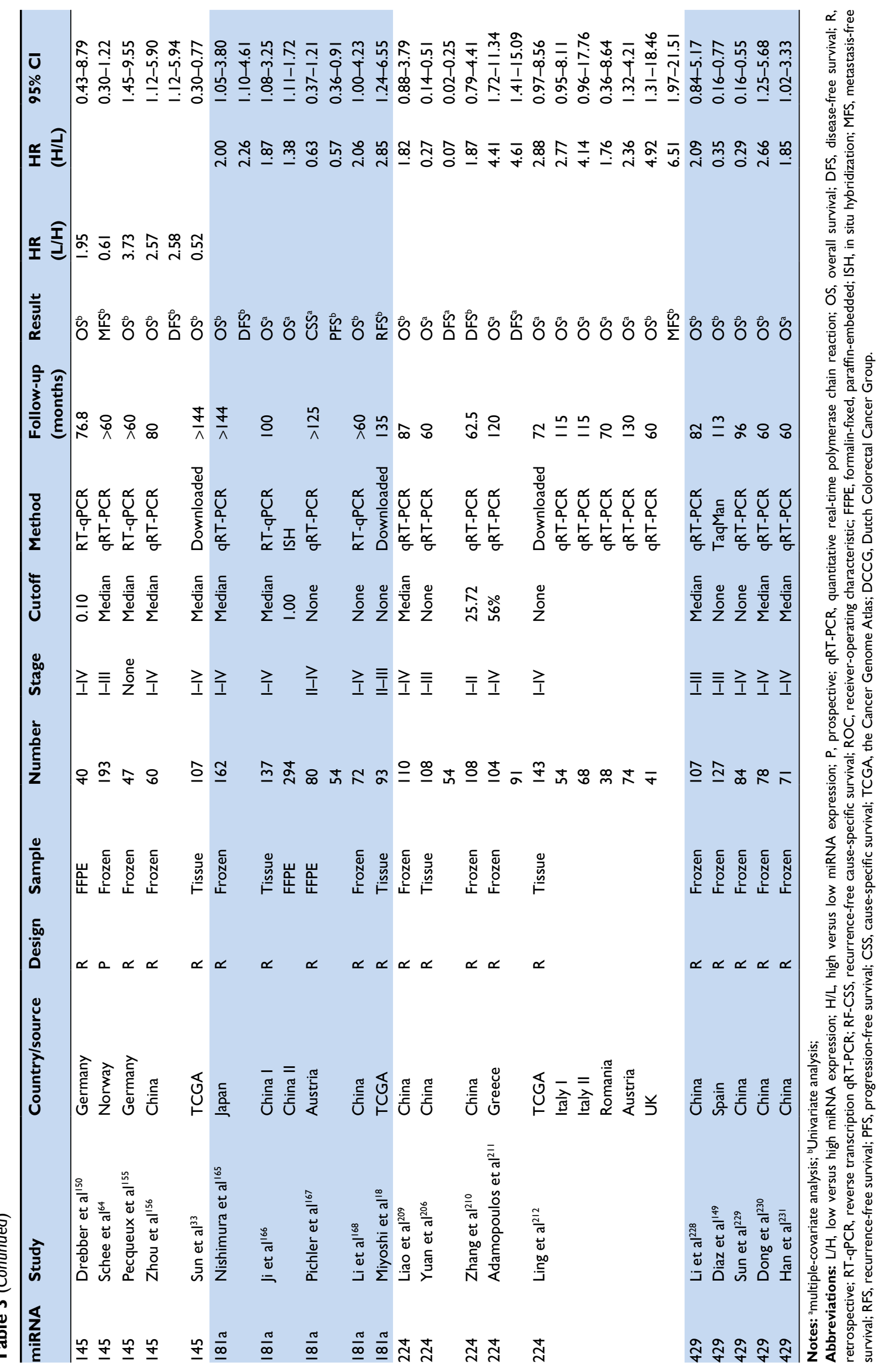


Table 4 Meta-analysis results for miRNA expression in colorectal cancer

\begin{tabular}{|c|c|c|c|c|c|c|c|c|c|}
\hline miRNA & Survival analysis & Articles & Studies included & HR & $95 \% \mathrm{Cl}$ & Figure & $P$-value & $\begin{array}{l}\text { Heterogeneity } \\
\left.\text { (Higgins's } I^{2}\right)\end{array}$ & $\begin{array}{l}\text { Patients, } \\
\text { n }\end{array}$ \\
\hline High miR2I & OS & 3 & $4,5,7$ & 1.56 & $0.47-5.23$ & 2 & 0.47 & $85.2 \%, P<0.01$ & 616 \\
\hline High miR2I & DFS & 3 & $4,6,7$ & 1.39 & $0.49-3.96$ & 2 & 0.53 & $84.4 \%, P<0.01$ & 480 \\
\hline High miR92a & OS & 2 & 10,13 & 2.11 & $0.59-7.61$ & 2 & 0.25 & $81.6 \%, P=0.02$ & 240 \\
\hline High miRI4I & OS & 2 & 14,19 & 2.52 & $1.68-3.77$ & 2 & $<0.01$ & $0.0 \%, P=0.87$ & 426 \\
\hline High miR200b & OS & 2 & 14,16 & 1.28 & $0.75-2.19$ & 2 & 0.36 & $88.8 \%, P<0.01$ & 696 \\
\hline High miR203 & OS & 2 & 24,25 & 0.99 & $0.22-4.37$ & 2 & 0.99 & $91.4 \%, P<0.01$ & 366 \\
\hline High miR2I & OS & 13 & $5,60-68,70-73$ & 1.31 & $1.12-1.53$ & $3 \mathrm{~A}$ & $<0.01$ & $65.3 \%, P<0.01$ & 2,861 \\
\hline High miR2I & $\mathrm{OS}^{\mathrm{a}}$ & 8 & $5,60,63,65,66,68,7 I, 73$ & 1.47 & $1.16-1.87$ & $3 \mathrm{~A}$ & $<0.01$ & $71.7 \%, P<0.01$ & 2,372 \\
\hline High miR2I & DFS & 7 & $58-61,67,68,70$ & 1.64 & $|| I-2.4 \mid$. & $3 D$ & 0.01 & $79.2 \%, P<0.01$ & 554 \\
\hline High miR2I & RFS/CSS/MFS/PFS & 5 & $63,64,69,71,73$ & 1.33 & $1.06-1.67$ & $3 D$ & 0.01 & $48.6 \%, P=0.07$ & $\mathrm{I}, 787$ \\
\hline High miR2I & OS, adjusted ${ }^{b}$ & & & 1.13 & $0.96-1.34$ & $4 B$ & 0.15 & $71.6 \%, P<0.01$ & \\
\hline High miRI06a & OS & 5 & $49,67,112-114$ & 1.31 & $0.72-2.36$ & 5 & 0.38 & $62.2 \%, P=0.03$ & 403 \\
\hline High miRI06a & DFS/MFS & 5 & $49,64,67,111,113$ & 1.14 & $0.55-2.36$ & 5 & 0.72 & $75.8 \%, P<0.01$ & 519 \\
\hline High miRI25b & OS & 5 & $33,35,106,112,119$ & 1.43 & $0.83-2.47$ & 5 & 0.19 & $74.6 \%, P<0.01$ & 857 \\
\hline Low miRI26 & OS & 5 & $120,122-125$ & 1.55 & $1.24-1.93$ & 6 & $<0.01$ & $1.2 \%, P=0.40$ & 948 \\
\hline Low miR I26 & PFS/RFS/CSS & 3 & $120-122$ & 1.72 & $0.95-3.10$ & 6 & 0.07 & $75.2 \%, P=0.02$ & 732 \\
\hline Low miR I 43 & DFS/CSS/PFS & 3 & $59,151,153$ & 1.00 & $0.47-2.13$ & 6 & 1.00 & $77.7 \%, P<0.01$ & 230 \\
\hline Low miRI43 & OS & 3 & $112,150,152$ & 1.69 & $0.94-3.04$ & 6 & 0.08 & $0.0 \%, P=0.69$ & 159 \\
\hline Low miR I45 & OS & 4 & $33,150,155,156$ & 1.68 & $0.55-5.12$ & 7 & 0.36 & $85.4 \%, P<0.01$ & 254 \\
\hline Low miR I45 & MFS/DFS & 2 & 64,156 & 1.23 & $0.30-5.06$ & 7 & 0.77 & $85.1 \%, P<0.01$ & 253 \\
\hline High miRI8Ia & OS & 3 & $165,166,168$ & 1.52 & $1.26-1.83$ & 7 & $<0.01$ & $0.0 \%, P=0.45$ & 665 \\
\hline High miRI8Ia & DFS/CSS/PFS/RFS & 3 & $18,165,167$ & 1.17 & $0.53-2.59$ & 7 & 0.69 & $84.0 \%, P<0.01$ & 309 \\
\hline High miR224 & OS & 4 & $206,209,211,212$ & 2.12 & $1.04-4.34$ & 8 & 0.04 & $80.9 \%, P<0.01$ & 740 \\
\hline High miR224 & DFS/MFS & 4 & $206,210-212$ & 1.43 & $0.23-8.77$ & 8 & 0.70 & $90.6 \%, P<0.01$ & 294 \\
\hline High miR429 & OS & 5 & $|46,228-23|$ & 1.00 & $0.39-2.58$ & 8 & 1.00 & $88.7 \%, P<0.01$ & 467 \\
\hline
\end{tabular}

Notes: aMultiple-covariate analysis; badjusted with trim-and-fill method.

Abbreviations: OS, overall survival; DFS, disease-free survival; RFS, recurrence-free survival; CSS, cause-specific survival; MFS, metastasis-free survival; PFS, progression-free survival.

miR200b, miR203, miR224, and miR429. Results of survival analyses of these miRNAs are given in Figures 2-8.

\section{CRC patients with high blood miR I4I,} high tissue miR I8Ia and miR224, or low tissue miR 126 expression have significantly shorter OS

Two studies ${ }^{14,19}$ focused on associations between high blood miR141 levels and OS, indicating that CRC patients with high blood miR141 levels had significantly shorter OS than those with low miR141 expression (HR 2.52, 95\% CI 1.68-3.77, $P<0.01$; Figure 2). Five papers ${ }^{120,122-125}$ stressed connections between low tissue miR126 levels and OS, suggesting that CRC patients with low expression of tissue miR126 levels had significantly poorer OS than those with high miR126 expression (HR 1.55, 95\% CI 1.24-1.93, $P<0.01$; Figure 6).

Three articles concentrated on the relationship between high tissue miR181a levels and OS, demonstrating that CRC patients with high miR181a levels had significantly worse OS than those with low miR181a expression (HR 1.52, 95\% CI 1.26-1.83, $P<0.01$; Figure 7). Four studies paid attention to correlations between high expression of tissue miR224 levels and OS, showing that CRC patients with high tissue miR224 levels had significantly shorter OS than those with low miR224 expression (HR 2.12, 95\% CI 1.04-4.34, $P=0.04$; Figure 8 ).

\section{There was no significant relationship} between high expression levels of blood miR2I, miR92a, miR200b, miR203, tissue miR I06a, miRI25b, or miR429 or low expression levels of tissue miR I43 or miRI45 and OS

Details are given in Table 4 and Figures 2 and 5-8.

\section{High tissue miR2I expression forecasts poor OS}

Thirteen investigations $\mathbf{s}^{5,60-68,70-73}$ analyzed the connection between high tissue miR21 levels and OS, showing that CRC patients with high tissue miR21 levels had significantly worse OS than those with low miR21 expression (HR 1.31, 95\% CI 1.12-1.53, $P<0.01$; Figure 3A). 


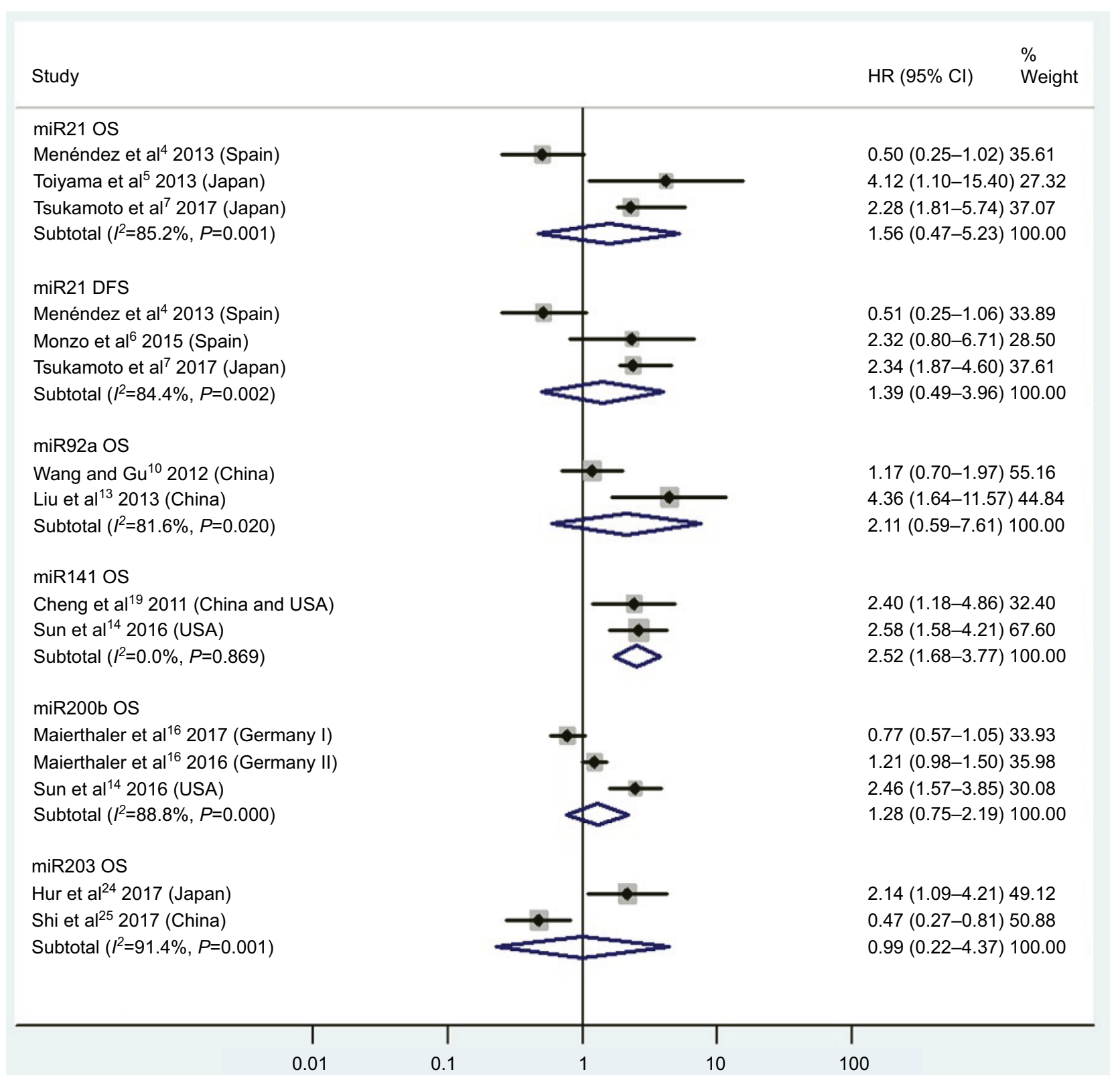

Figure 2 Pooled analyses of OS or DFS in association with high blood miR2I-, miR92a-, miRI4I-, miR200b-, and miR203-expression levels. Note: Weights are from random-effect analysis.

Abbreviations: OS, overall survival; DFS, disease-free survival.

\section{Publication bias}

To assess publications showing some degree of bias for OS of CRC patients with high tissue miR21 levels, our study used Begg's funnel plot (Figure 3B). The $P$-value was less than 0.01 , indicating the presence of publication bias. As such, the trim-and-fill method was performed and the pooled HR recalculated with presumed missing studies to estimate asymmetry in the funnel plot (Figure 4A), indicating no publication bias $(P=0.73)$. The recalculated HR changed significance for OS (HR 1.13, 95\% CI 0.96-1.34, $P=0.15$; Figure 4B).

\section{Sensitivity analysis}

For research on OS of CRC patients with high tissue miR21 levels, the sensitivity analysis did not manifest alterations during outcomes on the basis of the exclusion of any single investigation (Figure 3C), showing that no sole study significantly affected the merged HR or $95 \%$ CI. This also 
A

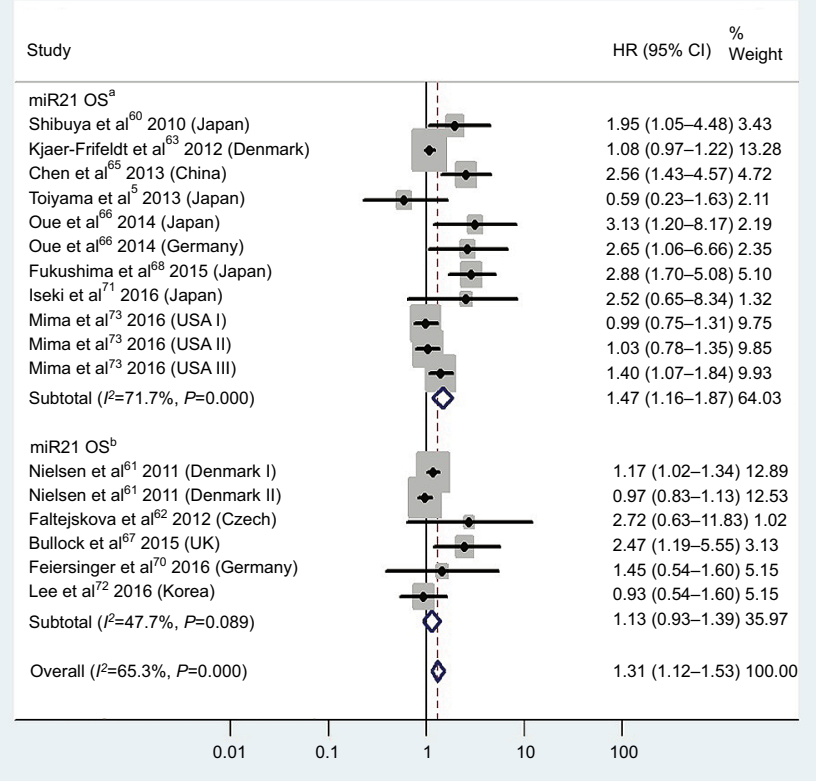

C

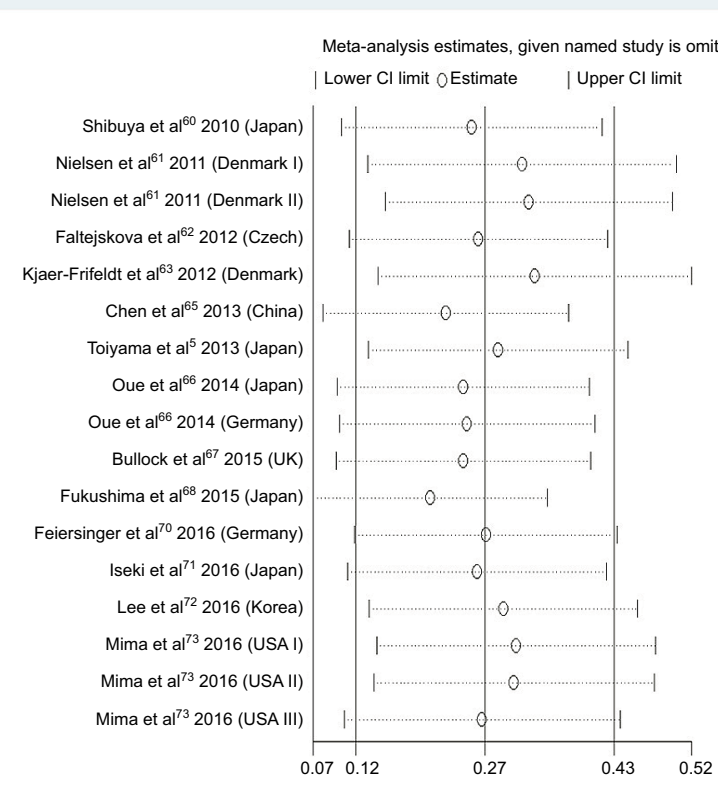

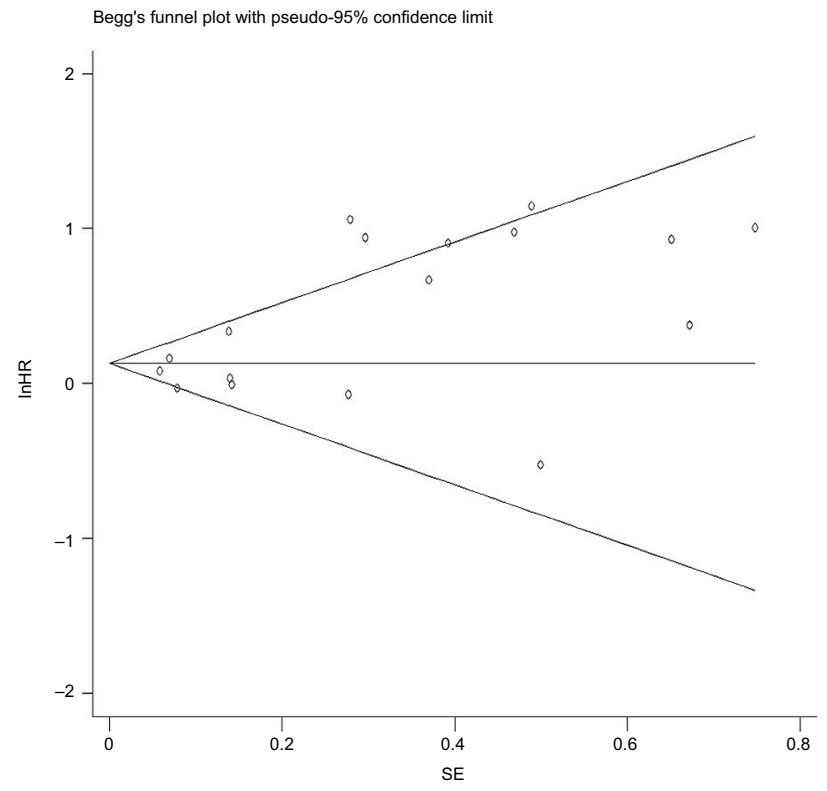

D

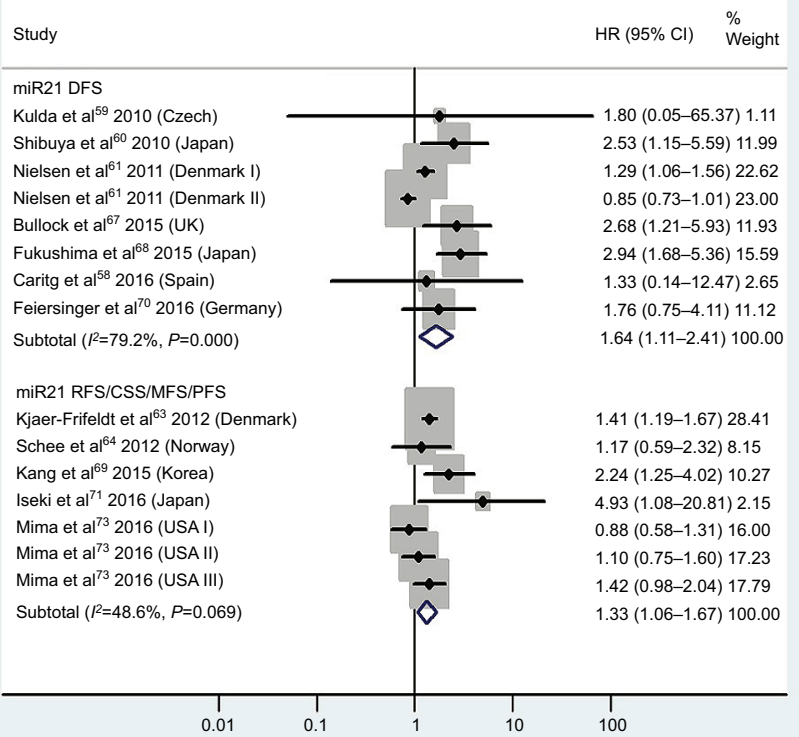

Figure 3 (A) Forest plots of pooled analyses of OS or OS (multiple-covariate analysis) in association with high tissue miR2I-expression levels; (B) Begg's funnel plot of publication bias for pooled analysis of OS in association with high tissue miR2I-expression levels; (C) sensitivity analysis of pooled analysis of OS in association with high tissue miR2I-expression levels; (D) forest plots of pooled analyses of DFS or RFS/CSS/MFS/PFS in association with high tissue miR2I-expression levels. Weights are from random-effects analysis in $A$ and $D$. a Multiple-covariate analysis; ${ }^{b}$ univariate analysis.

Abbreviations: OS, overall survival; DFS, disease-free survival; RFS, recurrence-free survival; CSS, cause-specific survival; MFS, metastasis-free survival; PFS, progressionfree survival.

proved true for the outcome of OS adjusted with the trimand-fill method (Figure 4C).

\section{Key findings}

We carried out a meta-analysis of 13 miRNAs and OS. Serving as the most investigated miRNA, miR21 (high tissue levels) in CRC showed significantly shorter OS than low tissue miR21 levels $(P<0.05)$. However, there was no significant relationship between high blood miR21 levels and OS $(P=0.47)$. The different detected sample types and relatively small sample capacity of the miR21 blood group (only three studies analyzing the relationship between blood miR21 levels and OS) may have been potential clinical reasons and caused the statistical significance between tissue and blood miR21 levels.

Encouragingly, the HR from analysis of the association between high tissue miR21 levels and OS (multiple-covariate analysis $)^{5,60,63,65,66,68,71,73}$ was 1.47 , which was greater than that 
A

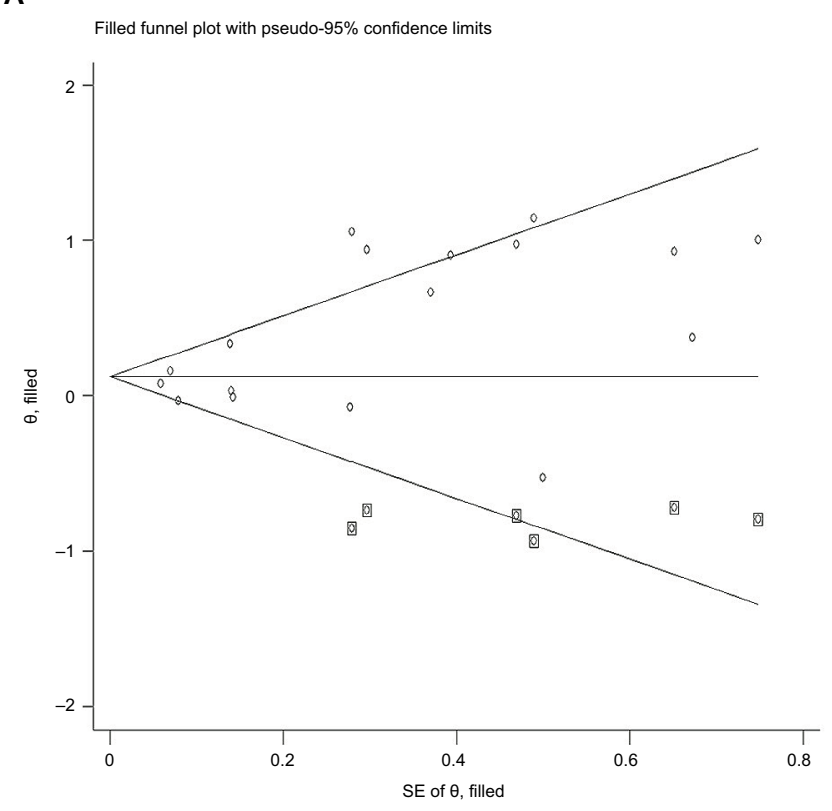

C
B

Study $\operatorname{miR} 1$ OS $^{\mathrm{a}}$ Shibuya et al60 2010 (Japan) Khibuya et al60 2010 (Japan) $1.95(1.05-4.48) 3.47$ Kjaer-Frifeldt et al
Chen et $a^{15}{ }^{65} 2012$ (China) Toiyama et al 2013 (Japan) Oue et al ${ }^{66} 2014$ (Japan) Oue et a ${ }^{66} 2014$ (Germany) Fukushima et al $6^{88} 2015$ (Japan) Iseki et $\mathrm{al}^{71} 2016$ (Japan) Mima et al $\mathrm{a}^{73} 2016$ (USA I) Mima et al ${ }^{73} 2016$ (USA III) Subtotal $\left(I^{2}=71.7 \%, P=0.000\right)$ miR21 Os ${ }^{\mathrm{b}}$ Nielsen et al $\mathrm{l}^{61} 2011$ (Denmark I) Nielsen et al ${ }^{61} 2011$ (Denmark II)

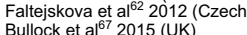
Bullock et a $\mathrm{al}^{7 / 2015}$ (UK) Feiersinger et al
Lee et al Subtotal $\left(I^{2}=47.7 \%, P=0.089\right)$

miR21 OS fill

fill (1)

fill (2)

fill ( 3 )
fill (4)
fill (5)

fill (5)
fill (6)

Subtotal $\left(l^{2}=0.0 \%, P=0.999\right)$

Overall $\left(I^{2}=71.6 \%, P=0.000\right)$

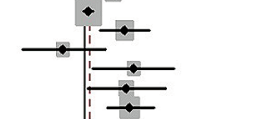

$2.56(1.43-4.57) 4.52$

$0.59(0.23-1.63) 2.27$

$3.13(1.20-8.17) 2.34$

$2.65(1.06-6.66) 2.49$

.88 (1.70-5.08) 4.82

$2.52(0.65-8.34) 1.47$

$1.99(0.75-1.31) 7.75$

$1.03(0.78-1.35) 7.81$

$1.47(1.16-1.87) 54.21$

$.17(1.02-1.34) 9.26$ $0.97(0.83-1.13) 9.10$ $2.72(0.63-11.83) 1.16$ $2.47(1.19-5.55) 3.21$
$1.45(0.39-5.43) 1.40$ $0.93(0.54-1.60) 4.85$ $1.13(0.93-1.39) 28.97$

$0.39(0.15-1.02) 2.34$ $0.43(0.25-0.74) 4.86$ $0.45(0.10-1.96) 1.13$

$0.48(0.27-0.16) 4.44$

$0.49(0.14-1.74) 1.51$

$0.45(0.33-0.62) 16.81$

$1.13(0.96-1.34) 100.00$

0.01

100

Meta-analysis estimates, given named study is omitted

| Lower $\mathrm{Cl}$ limitoEstimate |Upper $\mathrm{Cl}$ limit

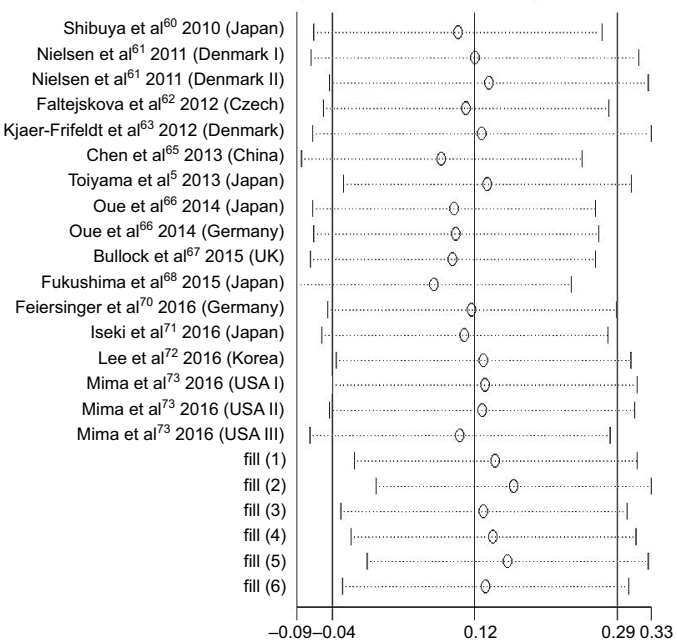

Figure 4 (A) Funnel plot of pooled analysis adjusted with the trim-and-fill method of OS in association with high tissue miR2I-expression levels. Circles, included studies; diamonds, presumed missing studies. (B) Forest plot of pooled analysis adjusted with the trim-and-fill method of OS in association with high tissue miR2I-expression levels. (C) Sensitivity analysis of pooled analysis adjusted with the trim-and-fill method of OS in association with high tissue miR2I-expression levels. Weights are from random-

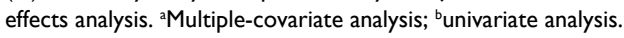

Abbreviation: OS, overall survival.

reported in any of the 13 articles..$^{5,60-78,70-73}$ Nevertheless, the significance did not remain in accordance with the forest plot, which was adjusted with the trim-and-fill method because publication bias existed $(P<0.01$; Figure $3 \mathrm{~B})$. This result indicated that the prognostic value of tissue miR21 was not stable in CRC patients. There were other miRNAs with significant prognostic value in CRC, including blood miR141 and tissue miR21, miR181a, miR224, and miR126 $(P<0.05)$. Among these, blood miR141 and tissue miR224 were powerful prognostic candidates in CRC (HR $\geq 2)$.

\section{Discussion}

\section{Present situation}

Increasing numbers of studies have indicated that diverse miRNAs are connected with survival results in CRC patients. ${ }^{1-258}$ Nevertheless, no systematic review or metaanalysis has evaluated HRs between miRNA levels and survival outcomes of CRC patients. Therefore, it was of vital significance to launch a meta-analysis to comprehend the relationship between expression levels of miRNAs and prognoses of CRC patients. 


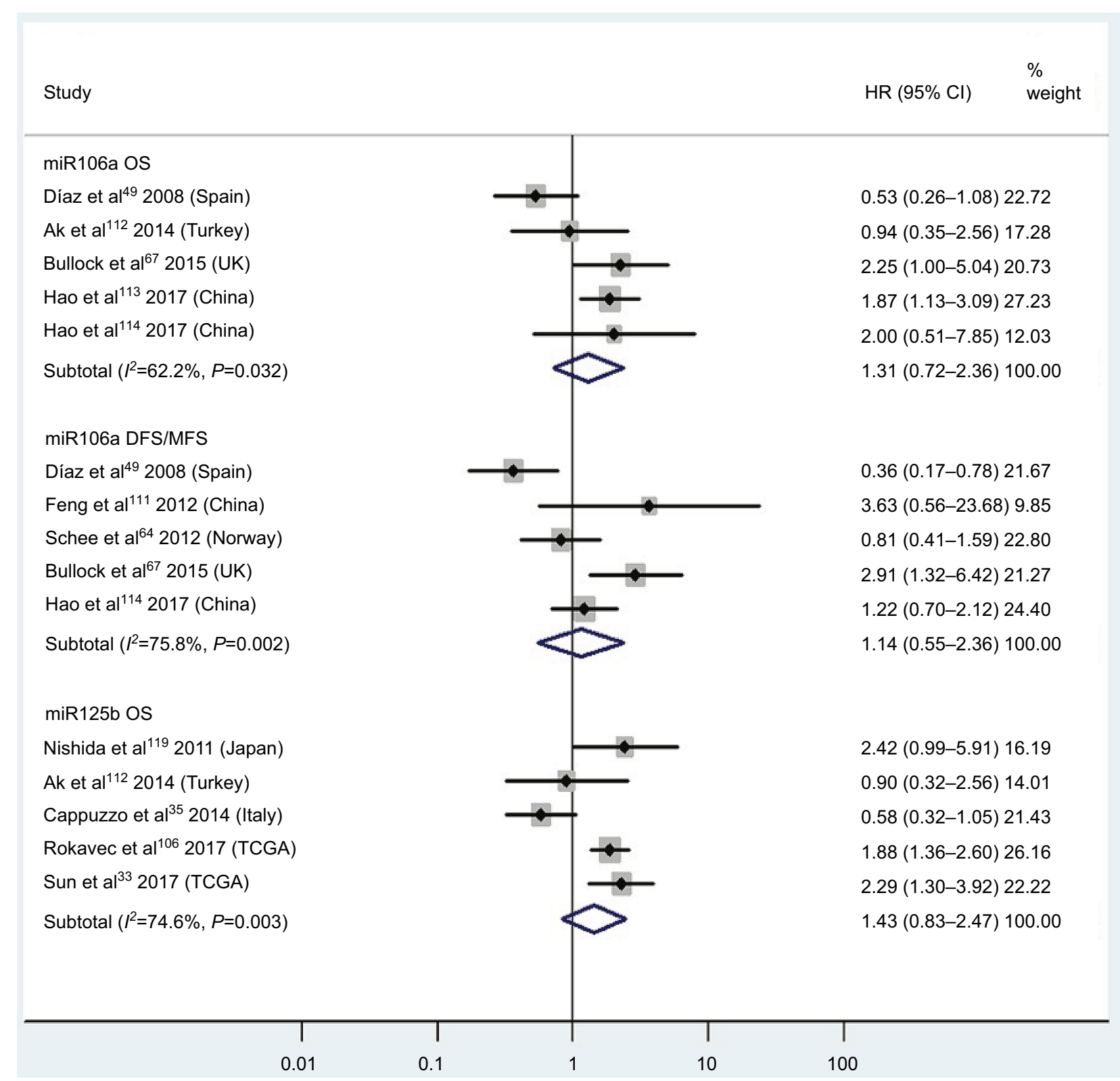

Figure 5 Pooled analyses of OS or DFS/MFS in association with high tissue miRI06a- and miR I25b-expression levels. Weights are from random-effects analysis. Abbreviations: OS, overall survival; DFS, disease-free survival; MFS, metastasis-free survival; TCGA, the Cancer Genome Atlas.

\section{Molecular mechanisms for miRNAs researched}

An overview of miRNAs with dysregulated expression and their potential targets and pathways of entry is detailed in Figure 9. There was noticeable functional overlap and relationships among the miRNAs. Seven miRNAs (miR21, miR106a, miR126, miR143, miR181a, miR224, and miR429) touched upon cell functions, including cell apoptosis, cell cycle, and death. To sum up, these associations may refer to CRC progression.

\section{Other CRC molecular pathways}

In addition to miRNAs, there are some other molecular data that can be confounders, related to mortalities, such as the chromosomal instability pathway, the DNA mismatch repair system, and microsatellite instability (MSI). Features of distinctive pathways are different models of genetic instability, succeeding clinical presentations, and features of pathological behavior. A majority of CRC follows the chromosomal instability pathway, features of which are extensive loss of heterozygosis and gross chromosomal 


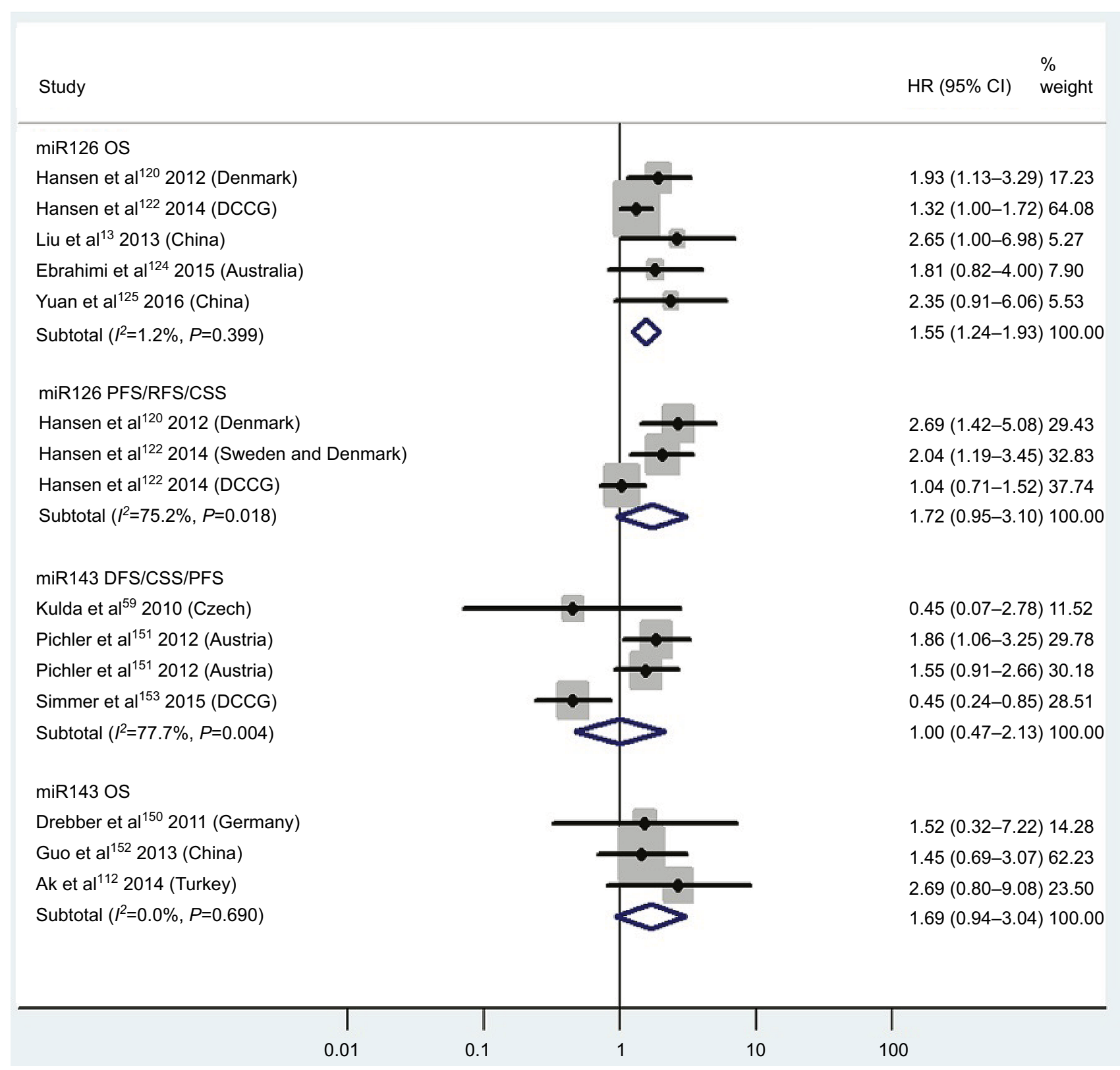

Figure 6 Pooled analyses of OS, PFS/RFS/CSS, or DFS/CSS/PFS in association with low tissue miRI26- and miRI43-expression levels. Weights are from random-effects analysis.

Abbreviations: OS, overall survival; DCCG, Dutch Colorectal Cancer Group; PFS, progression-free survival; RFS, recurrence-free survival; CSS, cause-specific survival; DFS, disease-free survival.

abnormalities. ${ }^{266,267}$ Second, about $15 \%$ of CRC is due to the derangement of the DNA mismatch repair system and consequential MSI. The former is in charge of protein production, which identifies and directly repairs mononucleotide mismatches at MS sequences that escape the proofreading system of DNA polymerase. Furthermore, a previous metaanalysis indicated that MSI-high CRC patients had a $40 \%$ better OS rate compared with MS-stable CRC patients. ${ }^{268}$

\section{Molecular pathological epidemiology (MPE)}

MPE is a multidisciplinary research field of associations between endogenous and exogenous ingredients, molecular cancer biomarkers, and cancer progression and also a comprehensive interdisciplinary science on the strength of the characteristic principal and continuum theory of diseases. ${ }^{269,270}$ Other than miRNAs, DNA mutation and methylation and other diagnostics, such as blood tests, also play crucial roles in cancer prognosis and MPE, which deeply investigates environmental exposure, intermediate phenotypes, such as blood biomarkers, and molecular changes in cancer using molecular pathologic analyses. MPE helps precision medicine by providing robust evidence for exposure-outcome associations, such as with drugs. 


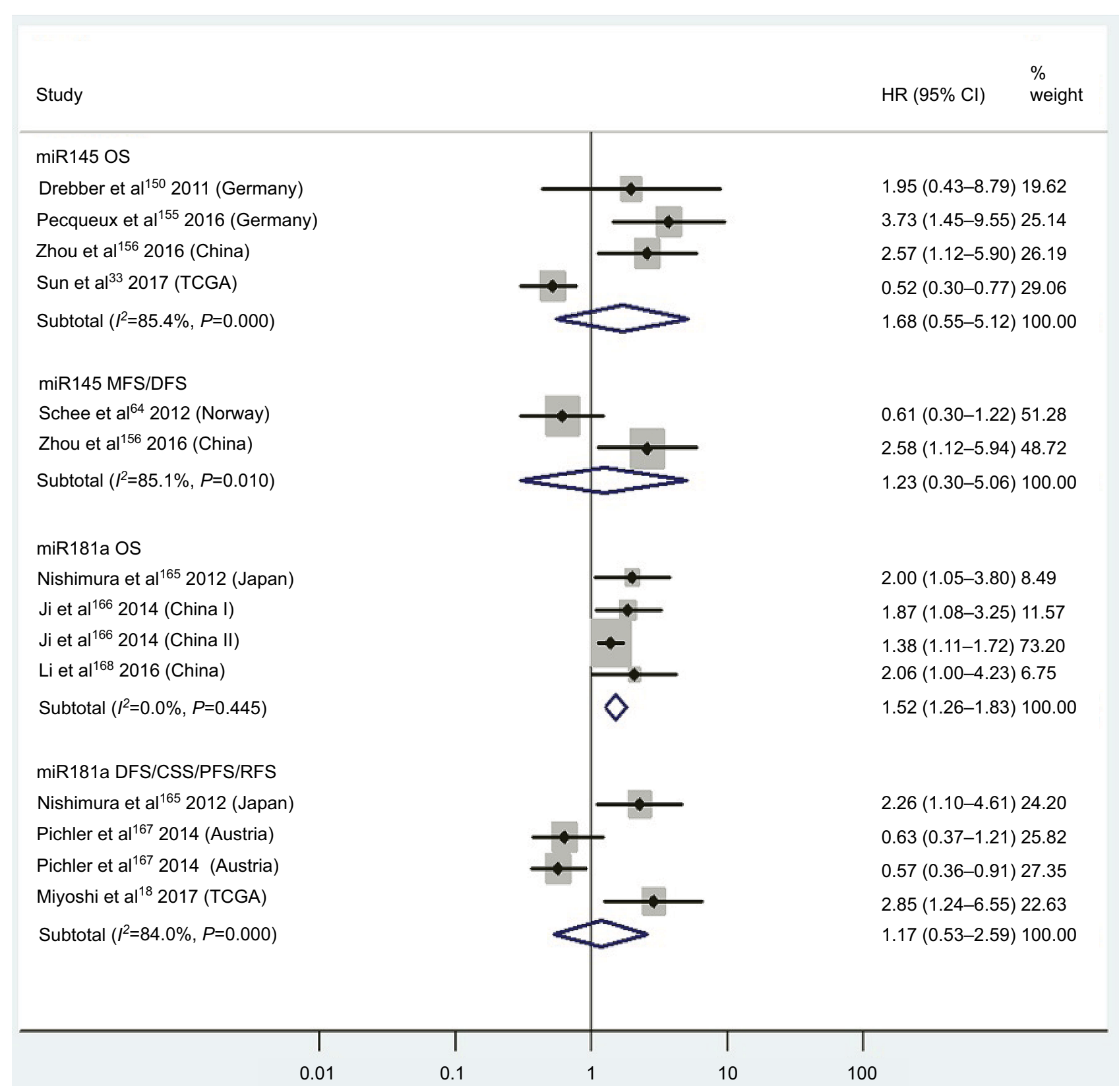

Figure 7 Pooled analyses of OS, MFS/DFS or DFS/CSS/PFS/RFS in association with high tissue miRI45-expression levels or low tissue miRI8Ia-expression levels. Weights are from random-effects analysis.

Abbreviations: OS, overall survival; TCGA, the Cancer Genome Atlas; MFS, metastasis-free survival; DFS, disease-free survival; CSS, cause-specific survival; PFS, progression-free survival; RFS, recurrence-free survival.

\section{Strengths}

This study has some strengths. Almost all the articles with survival consequences in CRC patients with disparate miRNAs were searched. Furthermore, the current expression profile of miRNAs is explicitly detailed in Tables 1 and 2 according to miRNAs and types of detected samples (blood or tissue). Papers assessing at least one of the survival curves of OS, CSS, DFS, RFS, PFS, and MFS were eventually included, and papers covering merely HRs or $95 \%$ CIs without any of the survival curves were excluded. Meta-analyses were performed on miRNAs investigated five or more times in CRC tissues. Virtually all the studies included had sample sizes $\geq 30$ (except two), ${ }^{70,111}$ reinforcing the usability and enlarging the feasibility of consequences to CRC patients.

\section{Limitations}

Nevertheless, we cannot overemphasize the following limitations. There was much heterogeneity in designs of studies, and most of the outcomes from our meta-analyses contained high heterogeneity $\left(I^{2} \geq 50 \%\right)$. Statistical assessment of publication 


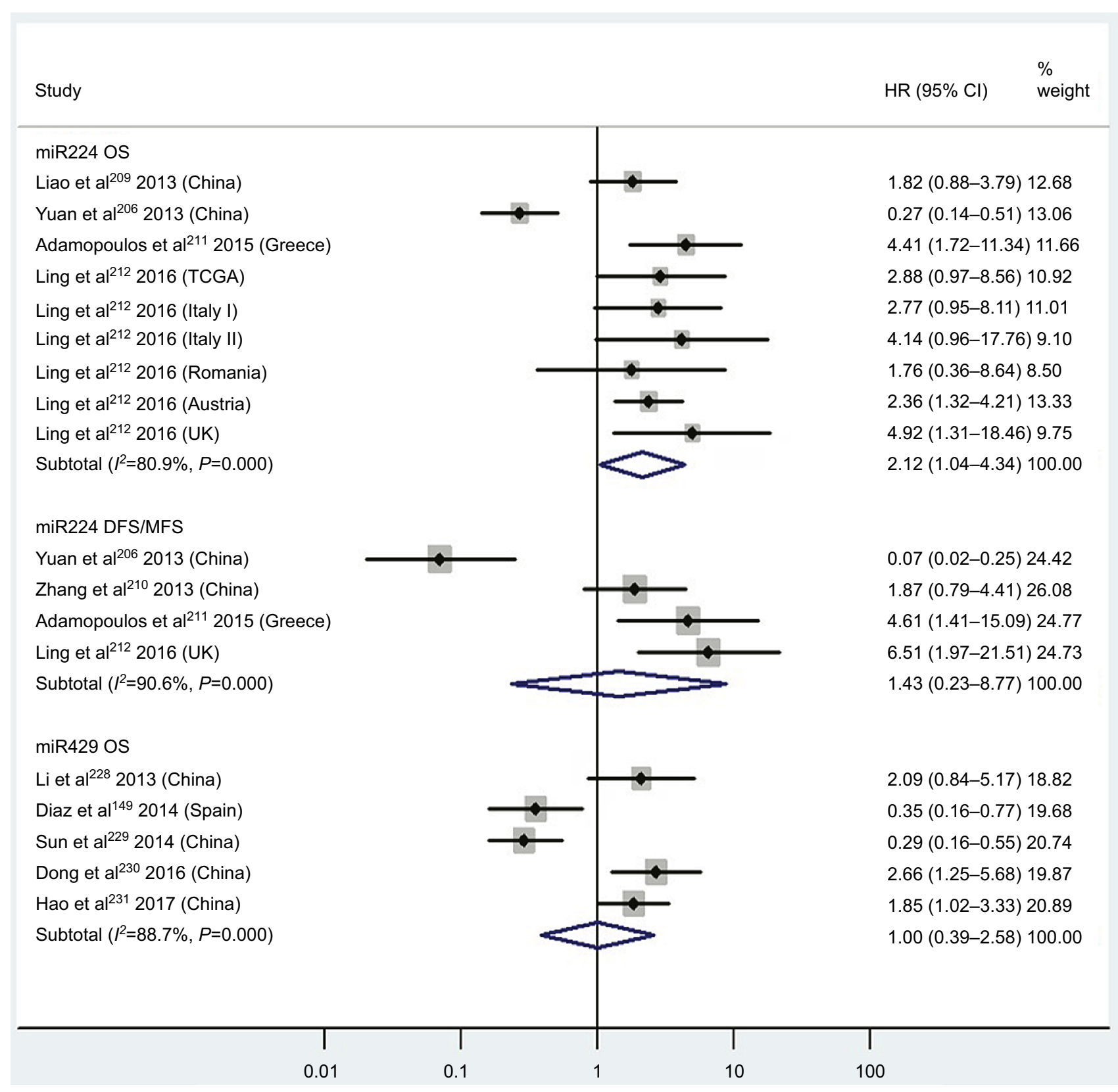

Figure 8 Pooled analyses of OS or DFS/MFS in association with high tissue miR224- and miR429-expression levels. Weights are from random-effects analysis. Abbreviations: OS, overall survival; TCGA, the Cancer Genome Atlas; DFS, disease-free survival; MFS, metastasis-free survival.

bias was suboptimal. There existed differences among the studies, including tissue-detected (frozen or formalin-fixed, paraffin-embedded), blood (plasma or serum), tumor stage (I-IV), cutoff values, and miRNA methods. The present metaanalysis simply included papers published in English, perhaps excluding potential studies published in other languages with respect to miRNA level and prognosis of CRC patients. Papers covering only HRs or $95 \%$ CIs without survival curves were excluded, lowering the sample sizes of the papers included. Because of the massive interrelation between papers and data about CRC, we subjectively and selectively included specific studies on the basis of the inclusion and exclusion criteria, bringing about the omission of several possible miRNAs with prognostic value and a relatively small number of included studies. The studies included contained three types of cancers (colon and rectal cancer and CRC), which blurred the division between tumor types. Some blood miRNAs were from cellfree RNA, while others were from exosome isolates. These were considered the same to some degree and may have caused some deviations in the final results. 


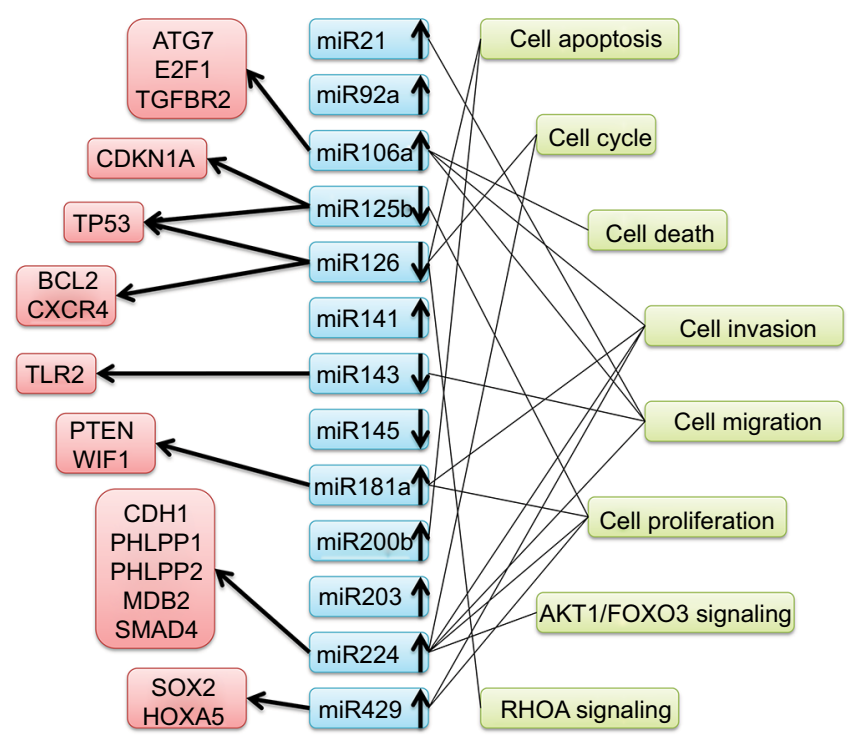

Figure 9 Summary of microRNAs with altered expression and potential targets and pathways entered in this study.

Abbreviations: ATG7, autophagy related 7; E2FI, E2F transcription factor I; TGFBR2, transforming growth factor beta receptor 2; CDKNIA, cyclin dependent kinase inhibitor IA; TP53, tumor protein P53; BCL2, apoptosis regulator; CXCR4, C-X-C motif chemokine receptor 4; TLR2, toll like receptor 2; PTEN, phosphatase and tensin homolog; WIFI, WNT inhibitory factor I; CDHI, cadherin I; PHLPPI, PH domain and leucine rich repeat protein phosphatase I; PHLPP2, PH domain and leucine rich repeat protein phosphatase 2; MBD2, methyl-CpG binding domain protein 2; SMAD4, SMAD family member 4; SOX2, SRY-box 2; HOXA5, homeobox A5; AKTI, AKT serine/ threonine kinase I; FOXO3, forkhead box O3; RHOA, ras homolog family member A.

\section{Implications for prospective clinical and scientific study}

It should be mentioned that the current meta-analysis is the first system assessment of the pertinence of miRNA level to the prognosis of CRC patients. This study presents foundations for prospective clinical and scientific study with respect to clinical staff and other health care providers, for whom simultaneous determination of miRNA expression is able greatly to reinforce assessment of life expectancy of CRC patients, thus enabling prompt therapy, and for scientific researchers. Current research progress and trends in connections between miRNAs and prognosis of CRC patients are shown in Tables 1 and 2. Selectively basic experiments can be conducted using these details (Figure 9). Conflicting results on the prognosis of miRNAs may be addressed based on the present meta-analysis.

\section{Conclusion}

In general, blood miR141 and tissue miR21, miR181a, miR224, and miR126 have significant prognostic value. Among these, blood miR141 and tissue miR224 are strong biomarkers of prognosis in CRC.

\section{Author contributions}

All authors contributed toward data analysis, drafting and critically revising the paper and agree to be accountable for all aspects of the work.

\section{Disclosure}

The authors report no conflicts of interest in this work.

\section{References}

1. Li J, Chen Y, Guo X, et al. Inhibition of miR-15b decreases cell migration and metastasis in colorectal cancer. Tumour Biol. 2016;37(7):8765-8773.

2. Li J, Liu Y, Wang C, et al. Serum miRNA expression profile as a prognostic biomarker of stage II/III colorectal adenocarcinoma. Sci Rep. 2015;5:12921.

3. Matsumura T, Sugimachi K, Iinuma $\mathrm{H}$, et al. Exosomal microRNA in serum is a novel biomarker of recurrence in human colorectal cancer. Br J Cancer. 2015;113(2):275-281.

4. Menéndez P, Padilla D, Villarejo P, et al. Prognostic implications of serum microRNA-21 in colorectal cancer. J Surg Oncol. 2013;108(6):369-373.

5. Toiyama Y, Takahashi M, Hur K, et al. Serum miR-21 as a diagnostic and prognostic biomarker in colorectal cancer. J Natl Cancer Inst. 2013;105(12):849-859.

6. Monzo M, Martínez-Rodenas F, Moreno I, et al. Differential MIR-21 expression in plasma from mesenteric versus peripheral veins: an observational study of disease-free survival in surgically resected colon cancer patients. Medicine (Baltimore). 2015;94(1):e145.

7. Tsukamoto M, Iinuma H, Yagi T, Matsuda K, Hashiguchi Y. Circulating exosomal microRNA-21 as a biomarker in each tumor stage of colorectal cancer. Oncology. 2017;92(6):360-370.

8. Kou CH, Zhou T, Han XL, Zhuang HJ, Qian HX. Downregulation of mir-23b in plasma is associated with poor prognosis in patients with colorectal cancer. Oncol Lett. 2016;12(6):4838-4844.

9. Jinushi T, Shibayama Y, Kinoshita I, et al. Low expression levels of microRNA-124-5p correlated with poor prognosis in colorectal cancer via targeting of SMC4. Cancer Med. 2014;3(6):1544-1552.

10. Wang LG, Gu J. Serum microRNA-29a is a promising novel marker for early detection of colorectal liver metastasis. Cancer Epidemiol. 2012;36(1):e61-e67.

11. Basati G, Razavi AE, Pakzad I, Malayeri FA. Circulating levels of the miRNAs, miR-194, and miR-29b, as clinically useful biomarkers for colorectal cancer. Tumour Biol. 2016;37(2):1781-1788. 
12. Schou JV, Rossi S, Jensen BV, et al. miR-345 in metastatic colorectal cancer: a non-invasive biomarker for clinical outcome in non-KRAS mutant patients treated with 3 rd line cetuximab and irinotecan. PLoS One. 2014;9(6):e99886.

13. Liu GH, Zhou ZG, Chen R, et al. Serum miR-21 and miR-92a as biomarkers in the diagnosis and prognosis of colorectal cancer. Tumour Biol. 2013;34(4):2175-2181.

14. Sun Y, Liu Y, Cogdell D, et al. Examining plasma microRNA markers for colorectal cancer at different stages. Oncotarget 2016;7(10):11434-11449.

15. Mao L, Feng W, Yu Y, Xu X. Serum expression of miRNA-103, a potential diagnostic and prognostic biomarker for colorectal cancer. Int J Clin Med. 2016;9(7):14212-14218.

16. Maierthaler M, Benner A, Hoffmeister M, et al. Plasma miR-122 and miR-200 family are prognostic markers in colorectal cancer. Int $J$ Cancer. 2017;140(1):176-187.

17. Kijima T, Hazama S, Tsunedomi R, et al. MicroRNA-6826 and-6875 in plasma are valuable non-invasive biomarkers that predict the efficacy of vaccine treatment against metastatic colorectal cancer. Oncol Rep 2017;37(1):23-30.

18. Miyoshi J, Toden S, Yoshida K, et al. MiR-139-5p as a novel serum biomarker for recurrence and metastasis in colorectal cancer. Sci Rep. 2017;7:43393.

19. Cheng H, Zhang L, Cogdell DE, et al. Circulating plasma MiR-141 is a novel biomarker for metastatic colon cancer and predicts poor prognosis. PLoS One. 2011;6(3):e17745.

20. Lv ZC, Fan YS, Chen HB, Zhao DW. Investigation of microRNA-155 as a serum diagnostic and prognostic biomarker for colorectal cancer. Tumour Biol. 2015;36(3):1619-1625.

21. Yuan D, Li K, Zhu K, Yan R, Dang C. Plasma miR-183 predicts recurrence and prognosis in patients with colorectal cancer. Cancer Biol Ther. 2015;16(2):268-275.

22. Xu C, Gu L. The diagnostic effect of serum miR-196b as biomarker in colorectal cancer. Biomed Rep. 2017;6(1):39-45.

23. Toiyama Y, Hur K, Tanaka K, et al. Serum miR-200c is a novel prognostic and metastasis-predictive biomarker in patients with colorectal cancer. Ann Surg. 2014;259(4):735-743.

24. Hur K, Toiyama Y, Okugawa Y, et al. Circulating microRNA-203 predicts prognosis and metastasis in human colorectal cancer. Gut 2017;66(4):654-665.

25. Shi SQ, Ke JJ, Wu WQ, Xu QS. Serum miRNA-203 expression is associated with chemo-response to standard FOLFOX treatment of patients with colorectal cancer. Int J Clin Exp Pathol. 2017;10(1): 105-116.

26. Pu XX, Huang GL, Guo HQ, et al. Circulating miR-221 directly amplified from plasma is a potential diagnostic and prognostic marker of colorectal cancer and is correlated with p53 expression. J Gastroenterol Hepatol. 2010;25(10):1674-1680.

27. Yu J, Jin L, Jiang L, et al. Serum miR-372 is a diagnostic and prognostic biomarker in patients with early colorectal cancer. Anticancer Agents Med Chem. 2016;16(4):424-431.

28. Hur K, Toiyama Y, Schetter AJ, et al. Identification of a metastasisspecific microRNA signature in human colorectal cancer. $J$ Natl Cancer Inst. 2015;107(3):dju492.

29. Imaoka H, Toiyama Y, Fujikawa H, et al. Circulating microRNA-1290 as a novel diagnostic and prognostic biomarker in human colorectal cancer. Ann Oncol. 2016;27(10):1879-1886.

30. Liu C, Eng C, Shen J, et al. Serum exosomal miR-4772-3p is a predictor of tumor recurrence in stage II and III colon cancer. Oncotarget 2016;7(46):76250-76260.

31. Liu TP, Huang CC, Yeh KT, et al. Down-regulation of let-7a-5p predicts lymph node metastasis and prognosis in colorectal cancer: implications for chemotherapy. Surg Oncol. 2016;25(4):429-434.

32. Xu M, Kuang Y, Wang M, Han X, Yang Q. A microRNA expression signature as a predictor of survival for colon adenocarcinoma. Neoplasma. 2017;64(1):56-64.
33. Sun $\mathrm{M}$, Song $\mathrm{H}$, Wang $\mathrm{S}$, et al. Integrated analysis identifies microRNA-195 as a suppressor of Hippo-YAP pathway in colorectal cancer. J Hematol Oncol. 2017;10(1):79.

34. Yang IP, Tsai HL, Miao ZF, et al. Development of a deregulating microRNA panel for the detection of early relapse in postoperative colorectal cancer patients. J Transl Med. 2016;14(1):108.

35. Cappuzzo F, Sacconi A, Landi L, et al. MicroRNA signature in metastatic colorectal cancer patients treated with anti-EGFR monoclonal antibodies. Clin Colorectal Cancer. 2014;13(1):37.e4-45.e4.

36. Molina-Pinelo S, Carnero A, Rivera F, et al. MiR-107 and miR-99a-3p predict chemotherapy response in patients with advanced colorectal cancer. BMC Cancer. 2014;14:656.

37. Salendo J, Spitzner M, Kramer F, et al. Identification of a microRNA expression signature for chemoradiosensitivity of colorectal cancer cells, involving miRNAs-320a, -224, -132 and let7g. Radiother Oncol. 2013;108(3):451-457.

38. Kahlert C, Klupp F, Brand K, et al. Invasion front-specific expression and prognostic significance of microRNA in colorectal liver metastases. Cancer Sci. 2011;102(10):1799-1807.

39. Suto T, Yokobori T, Yajima R, et al. MicroRNA-7 expression in colorectal cancer is associated with poor prognosis and regulates cetuximab sensitivity via EGFR regulation. Carcinogenesis. 2015;36(3):338-345.

40. Nagano Y, Toiyama Y, Okugawa Y, et al. MicroRNA-7 is associated with malignant potential and poor prognosis in human colorectal cancer. Anticancer Res. 2016;36(12):6521-6526.

41. Zhu M, Xu Y, Ge M, Gui Z, Yan F. Regulation of UHRF1 by microRNA-9 modulates colorectal cancer cell proliferation and apoptosis. Cancer Sci. 2015;106(7):833-839.

42. Nishida N, Yamashita S, Mimori K, et al. MicroRNA-10b is a prognostic indicator in colorectal cancer and confers resistance to the chemotherapeutic agent 5-fluorouracil in colorectal cancer cells. Ann Surg Oncol. 2012;19(9):3065-3071.

43. Pizzini S, Bisognin A, Mandruzzato S, et al. Impact of microRNAs on regulatory networks and pathways in human colorectal carcinogenesis and development of metastasis. BMC Genomics. 2013;14:589.

44. Jiang H, Liu J, Chen Y, Ma C, Li B, Hao T. Up-regulation of mir-10b predicate advanced clinicopathological features and liver metastasis in colorectal cancer. Cancer Med. 2016;5(10):2932-2941.

45. Kontos CK, Tsiakanikas P, Avgeris M, Papadopoulos IN, Scorilas A. miR-15a-5p, a novel prognostic biomarker, predicting recurrent colorectal adenocarcinoma. Mol Diagn Ther. 2017;21(4):453-464.

46. Xiao G, Tang H, Wei W, Li J, Ji L, Ge J. Aberrant expression of microRNA-15a and microRNA-16 synergistically associates with tumor progression and prognosis in patients with colorectal cancer. Gastroenterol Res Pract. 2014;2014:364549.

47. Qian J, Jiang B, Li M, Chen J, Fang M. Prognostic significance of microRNA-16 expression in human colorectal cancer. World J Surg. 2013;37(12):2944-2949.

48. Diamantopoulos MA, Kontos CK, Kerimis D, Papadopoulos IN, Scorilas A. Upregulated miR-16 expression is an independent indicator of relapse and poor overall survival of colorectal adenocarcinoma patients. Clin Chem Lab Med. 2017;55(5):737-747.

49. Díaz R, Silva J, García JM, et al. Deregulated expression of miR-106a predicts survival in human colon cancer patients. Genes Chromosomes Cancer. 2008;47(9):794-802.

50. Ma Y, Zhang P, Wang F, et al. Elevated oncofoetal miR-17-5p expression regulates colorectal cancer progression by repressing its target gene P130. Nat Commun. 2012;3:1291.

51. Fang L, Li H, Wang L, et al. MicroRNA-17-5p promotes chemotherapeutic drug resistance and tumour metastasis of colorectal cancer by repressing PTEN expression. Oncotarget. 2014;5(10):2974-2987.

52. Yu G, Tang JQ, Tian ML, et al. Prognostic values of the miR-17-92 cluster and its paralogs in colon cancer. J Surg Oncol. 2012;106(3):232-237.

53. Motoyama K, Inoue $\mathrm{H}$, Takatsuno $\mathrm{Y}$, et al. Over- and underexpressed microRNAs in human colorectal cancer. Int J Oncol. 2009;34(4):1069-1075. 
54. Wu CW, Dong YJ, Liang QY, et al. MicroRNA-18a attenuates DNA damage repair through suppressing the expression of ataxia telangiectasia mutated in colorectal cancer. PLoS One. 2013;8(2):e57036.

55. Chen X, Shi K, Wang Y, et al. Clinical value of integrated-signature miRNAs in colorectal cancer: miRNA expression profiling analysis and experimental validation. Oncotarget. 2015;6(35):37544-37556.

56. Cheng D, Zhao S, Tang H, et al. MicroRNA-20a-5p promotes colorectal cancer invasion and metastasis by downregulating Smad4. Oncotarget. 2016;7(29):45199-45213.

57. Zhang GJ, LiY, Zhou H, Xiao HX, Zhou T. miR-20a is an independent prognostic factor in colorectal cancer and is involved in cell metastasis. Mol Med Rep. 2014;10(1):283-291.

58. Caritg O, Navarro A, Moreno I, et al. Identifying high-risk stage II colon cancer patients: a three-microRNA-based score as a prognostic biomarker. Clin Colorectal Cancer. 2016;15(4):e175-e182.

59. Kulda V, Pesta M, Topolcan O, et al. Relevance of miR-21 and miR143 expression in tissue samples of colorectal carcinoma and its liver metastases. Cancer Genet Cytogenet. 2010;200(2):154-160.

60. Shibuya H, Iinuma H, Shimada R, Horiuchi A, Watanabe T. Clinicopathological and prognostic value of microRNA-21 and microRNA-155 in colorectal cancer. Oncology. 2010;79(3-4):313-320.

61. Nielsen BS, Jørgensen S, Fog JU, et al. High levels of microRNA-21 in the stroma of colorectal cancers predict short disease-free survival in stage II colon cancer patients. Clin Exp Metastasis. 2011;28(1):27-38.

62. Faltejskova P, Besse A, Sevcikova S, et al. Clinical correlations of miR-21 expression in colorectal cancer patients and effects of its inhibition on DLD1 colon cancer cells. Int $J$ Colorectal Dis. 2012;27(11):1401-1408.

63. Kjaer-Frifeldt S, Hansen TF, Nielsen BS, et al. The prognostic importance of miR-21 in stage II colon cancer: a population-based study. $\mathrm{Br}$ J Cancer. 2012;107(7):1169-1174.

64. Schee K, Boye K, Abrahamsen TW, Fodstad Ø, Flatmark K. Clinical relevance of microRNA miR-21, miR-31, miR-92a, miR-101, miR106a and miR-145 in colorectal cancer. BMC Cancer. 2012;12:505.

65. Chen TH, Chang SW, Huang CC, et al. The prognostic significance of APC gene mutation and miR-21 expression in advanced-stage colorectal cancer. Colorectal Dis. 2013;15(11):1367-1374.

66. Oue N, Anami K, Schetter AJ, et al. High miR-21 expression from FFPE tissues is associated with poor survival and response to adjuvant chemotherapy in colon cancer. Int J Cancer. 2014;134(8):1926-1934.

67. Bullock MD, Pickard K, Mitter R, et al. Stratifying risk of recurrence in stage II colorectal cancer using deregulated stromal and epithelial microRNAs. Oncotarget. 2015;6(9):7262-7279.

68. Fukushima Y, Iinuma H, Tsukamoto M, Matsuda K, Hashiguchi Y. Clinical significance of microRNA-21 as a biomarker in each Dukes' stage of colorectal cancer. Oncol Rep. 2015;33(2):573-582.

69. Kang WK, Lee JK, Oh ST, Lee SH, Jung CK. Stromal expression of miR-21 in T3-4a colorectal cancer is an independent predictor of early tumor relapse. BMC Gastroenterol. 2015;15:2.

70. Feiersinger F, Nolte E, Wach S, et al. MiRNA-21 expression decreases from primary tumors to liver metastases in colorectal carcinoma. PLoS One. 2016;11(2):e0148580.

71. Iseki Y, Shibutani M, Maeda K, et al. Prognostic significance of microRNA-21 expression in patients with unresectable metastatic colon cancer. Anticancer Res. 2016;36(10):5145-5151.

72. Lee KS, Nam SK, Koh J, et al. Stromal expression of microRNA-21 in advanced colorectal cancer patients with distant metastases. J Pathol Transl Med. 2016;50(4):270-277.

73. Mima K, Nishihara R, Yang J, et al. MicroRNA MIR21 (miR-21) and PTGS2 expression in colorectal cancer and patient survival. Clin Cancer Res. 2016;22(15):3841-3848.

74. Zhang G, Xia S, Tian H, Liu Z, Zhou T. Clinical significance of miR-22 expression in patients with colorectal cancer. Med Oncol. 2012;29(5):3108-3112.

75. Li B, Li B, Sun H, Zhang H. The predicted target gene validation, function, and prognosis studies of miRNA-22 in colorectal cancer tissue. Tumour Biol. 2017;39(3):1010428317692257.
76. Zhou X, Xu X, Wang J, Lin J, Chen W. Identifying miRNA/mRNA negative regulation pairs in colorectal cancer. Sci Rep. 2015;5:12995.

77. Wu S, Bai L, Li ZF, Li QG, Xie J, Jian B. Clinical significance and prognostic value of microRNA-23b expression level in colon cancer. Int J Clin Exp Pathol. 2016;9(10):10587-10592.

78. Gao Y, Liu Y, Du L, et al. Down-regulation of miR-24-3p in colorectal cancer is associated with malignant behavior. Med Oncol. 2015;32(1):362.

79. Kerimis D, Kontos CK, Christodoulou S, Papadopoulos IN, Scorilas A. Elevated expression of $\mathrm{miR}-24-3 \mathrm{p}$ is a potentially adverse prognostic factor in colorectal adenocarcinoma. Clin Biochem. 2017;50(6):285-292.

80. Li X, Yang C, Wang X, Zhang J, Zhang R, Liu R. The expression of miR-25 is increased in colorectal cancer and is associated with patient prognosis. Med Oncol. 2014;31(1):781.

81. Xu J, Zhao J, Zhang R. Four microRNAs signature for survival prognosis in colon cancer using TCGA data. Sci Rep. 2016;6:38306.

82. de Robertis M, Loiacono L, Fusilli C, et al. Dysregulation of EGFR pathway in EphA2 cell subpopulation significantly associates with poor prognosis in colorectal cancer. Clin Cancer Res. 2017;23(1): 159-170.

83. Weissmann-Brenner A, Kushnir M, Yanai GL, et al. Tumor microRNA$29 \mathrm{a}$ expression and the risk of recurrence in stage II colon cancer. Int J Oncol. 2012;40(6):2097-2103.

84. Tang W, Zhu Y, Gao J, et al. MicroRNA-29a promotes colorectal cancer metastasis by regulating matrix metalloproteinase 2 and E-cadherin via KLF4. Br J Cancer. 2014;110(2):450-458.

85. Inoue A, Yamamoto H, Uemura M, et al. MicroRNA-29b is a novel prognostic marker in colorectal cancer. Ann Surg Oncol. 2015;22(Suppl 3):S1410-S1418.

86. Yang LH, Yin SY, He RQ, et al. Prospective target genes and pathways of miR-30a-5p in colorectal cancer: an investigation using TCGA and bioinformatics analysis. Int J Clin Exp Med. 2017;10(3):4373-4385.

87. Zhang Q, Tang Q, Qin D, et al. Role of microRNA 30a targeting insulin receptor substrate 2 in colorectal tumorigenesis. Mol Cell Biol. 2015;35(6):988-1000.

88. Liao WT, Ye YP, Zhang NJ, et al. MicroRNA-30b functions as a tumour suppressor in human colorectal cancer by targeting KRAS, PIK3CD and BCL2. J Pathol. 2014;232(4):415-427.

89. Yan L, Qiu J, Yao J. Downregulation of microRNA-30d promotes cell proliferation and invasion by targeting LRH-1 in colorectal carcinoma. Int J Mol Med. 2017;39(6):1371-1380.

90. Manceau G, Imbeaud S, Thiébaut R, et al. Hsa-miR-31-3p expression is linked to progression-free survival in patients with KRAS wild-type metastatic colorectal cancer treated with anti-EGFR therapy. Clin Cancer Res. 2014;20(12):3338-3347.

91. Mlcochova J, Faltejskova-Vychytilova P, Ferracin M, et al. MicroRNA expression profiling identifies miR-31-5p/3p as associated with time to progression in wild-type RAS metastatic colorectal cancer treated with cetuximab. Oncotarget. 2015;6(36):38695-38704.

92. Igarashi H, Kurihara H, Mitsuhashi K, et al. Association of microRNA31-5p with clinical efficacy of anti-EGFR therapy in patients with metastatic colorectal cancer. Ann Surg Oncol. 2015;22(8): 2640-2648.

93. Kiss I, Mlcochova J, Bortlicek Z, et al. Efficacy and toxicity of panitumumab after progression on cetuximab and predictive value of MiR-31-5p in metastatic wild-type KRAS colorectal cancer patients. Anticancer Res. 2016;36(9):4955-4959.

94. Yang MH, Yu J, Chen N, et al. Elevated microRNA-31 expression regulates colorectal cancer progression by repressing its target gene SATB2. PLoS One. 2013;8(12):e85353.

95. Chen T, Yao LQ, Shi Q, et al. MicroRNA-31 contributes to colorectal cancer development by targeting factor inhibiting HIF-1 $\alpha$ (FIH-1). Cancer Biol Ther. 2014;15(5):516-523.

96. Nosho K, Igarashi H, Nojima M, et al. Association of microRNA-31 with BRAF mutation, colorectal cancer survival and serrated pathway. Carcinogenesis. 2014;35(4):776-783. 
97. Wu W, Yang P, Feng X, et al. The relationship between and clinical significance of microRNA-32 and phosphatase and tensin homologue. Genes Chromosomes Cancer. 2013;52(12):1133-1140.

98. Liao W, Gu C, Huang A, Yao J, Sun R. MicroRNA-33b inhibits tumor cell growth and is associated with prognosis in colorectal cancer patients. Clin Transl Oncol. 2016;18(5):449-456.

99. Gao J, Li N, Dong Y, et al. miR-34a-5p suppresses colorectal cancer metastasis and predicts recurrence in patients with stage II/III colorectal cancer. Oncogene. 2015;34(31):4142-4152.

100. Hiyoshi Y, Schetter AJ, Okayama H, et al. Increased microRNA-34b and-34c predominantly expressed in stromal tissues is associated with poor prognosis in human colon cancer. PLoS One. 2015;10(4): e0124899.

101. Zhou T, Zhang G, Liu Z, Xia S, Tian H. Overexpression of miR-92a correlates with tumor metastasis and poor prognosis in patients with colorectal cancer. Int J Colorectal Dis. 2013;28(1):19-24.

102. Ke TW, Wei PL, Yeh KT, Chen WT, Cheng YW. MiR-92a promotes cell metastasis of colorectal cancer through PTEN-mediated PI3K/ AKT pathway. Ann Surg Oncol. 2015;22(8):2649-2655.

103. Xiao ZG, Deng ZS, Zhang YD, Zhang Y, Huang ZC. Clinical significance of microRNA-93 downregulation in human colon cancer. Eur J Gastroenterol Hepatol. 2013;25(3):296-301.

104. Ress AL, Stiegelbauer V, Winter E, et al. MiR-96-5p influences cellular growth and is associated with poor survival in colorectal cancer patients. Mol Carcinog. 2015;54(11):1442-1450.

105. Rapti SM, Kontos CK, Papadopoulos IN, Scorilas A. High miR-96 levels in colorectal adenocarcinoma predict poor prognosis, particularly in patients without distant metastasis at the time of initial diagnosis. Tumour Biol. 2016;37(9):11815-11824.

106. Rokavec M, Horst D, Hermeking H. Cellular model of colon cancer progression reveals signatures of mRNAs, miRNA, lncRNAs, and epigenetic modifications associated with metastasis. Cancer Res. 2017;77(8):1854-1867

107. Li W, Chang J, Wang S, et al. miRNA-99b-5p suppresses liver metastasis of colorectal cancer by down-regulating mTOR. Oncotarget. 2015;6(27):24448-24462.

108. Chen P, Xi Q, Wang Q, Wei P. Downregulation of microRNA-100 correlates with tumor progression and poor prognosis in colorectal cancer. Med Oncol. 2014;31(10):235.

109. Zheng YB, Xiao K, Xiao GC, et al. MicroRNA-103 promotes tumor growth and metastasis in colorectal cancer by directly targeting LATS2. Oncol Lett. 2016;12(3):2194-2200.

110. Yue B, Sun B, Liu C, et al. Long non-coding RNA Fer-1-like protein 4 suppresses oncogenesis and exhibits prognostic value by associating with miR-106a-5p in colon cancer. Cancer Sci. 2015;106(10): 1323-1332.

111. Feng B, Dong TT, Wang LL, et al. Colorectal cancer migration and invasion initiated by microRNA-106a. PLoS One. 2012;7(8): e43452.

112. Ak S, Tunca B, Tezcan G, et al. MicroRNA expression patterns of tumors in early-onset colorectal cancer patients. J Surg Res. 2014;191(1):113-122.

113. Hao H, Liu L, Zhang D, et al. Diagnostic and prognostic value of miR-106a in colorectal cancer. Oncotarget. 2017;8(3):5038-5047.

114. Hao H, Xia G, Wang C, Zhong F, Liu L, Zhang D. miR-106a suppresses tumor cells death in colorectal cancer through targeting ATG7. Med Mol Morphol. 2017;50(2):76-85.

115. Wang YX, Lang F, Liu YX, Yang CQ, Gao HJ. In situ hybridization analysis of the expression of miR-106b in colonic cancer. Int J Clin Exp Pathol. 2015;8(1):786-792.

116. Zhang GJ, Li JS, Zhou H, Xiao HX, Li Y, Zhou T. MicroRNA-106b promotes colorectal cancer cell migration and invasion by directly targeting DLC1. J Exp Clin Cancer Res. 2015;34:73.

117. Wang MJ, Li Y, Wang R, et al. Downregulation of microRNA-124 is an independent prognostic factor in patients with colorectal cancer. Int J Colorectal Dis. 2013;28(2):183-189.
118. Qiu Z, Guo W, Wang Q, et al. MicroRNA-124 reduces the pentose phosphate pathway and proliferation by targeting PRPS1 and RPIA mRNAs in human colorectal cancer cells. Gastroenterology. 2015;149(6):1587.e11-1598.e11.

119. Nishida N, Yokobori T, Mimori K, et al. MicroRNA miR-1205b is a prognostic marker in human colorectal cancer. Int J Oncol. 2011;38(5): 1437-1443.

120. Hansen TF, Sørensen FB, Lindebjerg J, Jakobsen A. The predictive value of microRNA-126 in relation to first line treatment with capecitabine and oxaliplatin in patients with metastatic colorectal cancer. BMC Cancer. 2012;12:83.

121. Hansen TF, Christensen RD, Andersen RF, Sørensen FB, Johnsson A, Jakobsen A. MicroRNA-126 and epidermal growth factorlike domain 7-an angiogenic couple of importance in metastatic colorectal cancer: results from the Nordic ACT trial. Br J Cancer. 2013;109(5):1243-1251.

122. Hansen TF, Kjær-Frifeldt S, Morgenthaler S, et al. The prognostic value of microRNA-126 and microvessel density in patients with stage II colon cancer: results from a population cohort. J Transl Med. 2014;12:254.

123. Liu Y, Zhou Y, Feng X, et al. Low expression of microRNA-126 is associated with poor prognosis in colorectal cancer. Genes Chromosomes Cancer. 2014;53(4):358-365.

124. Ebrahimi F, Gopalan V, Wahab R, Lu CT, Smith RA, Lam AK. Deregulation of miR-126 expression in colorectal cancer pathogenesis and its clinical significance. Exp Cell Res. 2015;339(2):333-341.

125. Yuan W, Guo YQ, Li XY, et al. MicroRNA-126 inhibits colon cancer cell proliferation and invasion by targeting the chemokine (C-X-C motif) receptor 4. Oncotarget. 2016;7(37):60230-60244.

126. Takahashi Y, Iwaya T, Sawada G, et al. Up-regulation of NEK2 by microRNA-128 methylation is associated with poor prognosis in colorectal cancer. Ann Surg Oncol. 2014;21(1):205-212.

127. Lu W, Wang J, Yang G, et al. Posttranscriptional regulation of galectin-3 by miR-128 contributes to colorectal cancer progression. Oncotarget. 2017;8(9):15242-15251.

128. Colangelo T, Fucci A, Votino C, et al. MicroRNA-130b promotes tumor development and is associated with poor prognosis in colorectal cancer. Neoplasia. 2013;15(9):1086-1099.

129. Zheng YB, Luo HP, Shi Q, et al. miR-132 inhibits colorectal cancer invasion and metastasis via directly targeting ZEB2. World J Gastroenterol. 2014;20(21):6515-6522.

130. Mokutani Y, Uemura M, Munakata K, et al. Down-regulation of microRNA-132 is associated with poor prognosis of colorectal cancer. Ann Surg Oncol. 2016;23(Suppl 5):599-608.

131. Wan TM, Lam CS, Ng L, et al. The clinicopathological significance of miR-133a in colorectal cancer. Dis Markers. 2014;2014:919283.

132. Wang LL, Du LT, Li J, et al. Decreased expression of miR-133a correlates with poor prognosis in colorectal cancer patients. World $J$ Gastroenterol. 2014;20(32):11340-11346.

133. Akçakaya P, Ekelund S, Kolosenko I, et al. miR-185 and miR-133b deregulation is associated with overall survival and metastasis in colorectal cancer. Int J Oncol. 2011;39(2):311-318.

134. Azizian A, Epping I, Kramer F, et al. Prognostic value of microRNAs in preoperative treated rectal cancer. Int J Mol Sci. 2016;17(4):568.

135. Xie Y, Song J, Zong Q, et al. Decreased expression of miR-134 and its clinical significance in human colorectal cancer. Hepatogastroenterology. 2015;62(139):615-619.

136. Gaedcke J, Grade M, Camps J, et al. The rectal cancer microRNAome: microRNA expression in rectal cancer and matched normal mucosa Clin Cancer Res. 2012;18(18):4919-4130.

137. Valeri N, Braconi C, Gasparini P, et al. MicroRNA-135b promotes cancer progression by acting as a downstream effector of oncogenic pathways in colon cancer. Cancer Cell. 2014;25(4):469-483.

138. Kan SF, Yang JS, Sun GX, Sun JJ. MicroRNA-135b is associated with tumor progression in colorectal cancer. Int J Clin Exp Med. 2016;9(3): $6533-6538$. 
139. Chen DL, Wang DS, Wu WJ, et al. Overexpression of paxillin induced by miR-137 suppression promotes tumor progression and metastasis in colorectal cancer. Carcinogenesis. 2013;34(4):803-811.

140. Smith AR, Marquez RT, Tsao WC, et al. Tumor suppressive microRNA-137 negatively regulates Musashi-1 and colorectal cancer progression. Oncotarget. 2015;6(14):12558-12573.

141. Qin YZ, Xie XC, Liu HZ, Lai H, Qiu H, Ge LY. Screening and preliminary validation of miRNAs with the regulation of hTERT in colorectal cancer. Oncol Rep. 2015;33(6):2728-2736.

142. Zhao L, Yu H, Yi S, et al. The tumor suppressor miR-138-5p targets PD-L1 in colorectal cancer. Oncotarget. 2016;7(29):45370-45384.

143. Long L, Huang G, Zhu H, Guo Y, Liu Y, Huo J. Down-regulation of miR-138 promotes colorectal cancer metastasis via directly targeting TWIST2. J Transl Med. 2013;11:275.

144. Liu X, Duan B, Dong Y, et al. MicroRNA-139-3p indicates a poor prognosis of colon cancer. Int J Clin Exp Pathol. 2014;7(11): 8046-8052.

145. Song M, Yin Y, Zhang J, et al. MiR-139-5p inhibits migration and invasion of colorectal cancer by downregulating AMFR and NOTCH1. Protein Cell. 2014;5(11):851-861.

146. Guo H, Hu X, Ge S, Qian G, Zhang J. Regulation of RAP1B by miR139 suppresses human colorectal carcinoma cell proliferation. Int $J$ Biochem Cell Biol. 2012;44(9):1465-1472.

147. Zhai H, Fesler A, Ba Y, Wu S, Ju J. Inhibition of colorectal cancer stem cell survival and invasive potential by hsa-miR-140-5p mediated suppression of Smad2 and autophagy. Oncotarget. 2015;6(23):19735-19746.

148. Zhang W, Zou C, Pan L, et al. MicroRNA-140-5p inhibits the progression of colorectal cancer by targeting VEGFA. Cell Physiol Biochem. 2015;37(3):1123-1133.

149. Diaz T, Tejero R, Moreno I, et al. Role of miR-200 family members in survival of colorectal cancer patients treated with fluoropyrimidines. J Surg Oncol. 2014;109(7):676-683.

150. Drebber U, Lay M, Wedemeyer I, et al. Altered levels of the oncomicroRNA 21 and the tumor-suppressor microRNAs 143 and 145 in advanced rectal cancer indicate successful neoadjuvant chemoradiotherapy. Int J Oncol. 2011;39(2):409-415.

151. Pichler M, Winter E, Stotz M, et al. Down-regulation of KRASinteracting miRNA-143 predicts poor prognosis but not response to EGFR-targeted agents in colorectal cancer. Br J Cancer. 2012;106(11):1826-1832.

152. Guo H, Chen Y, Hu X, Qian G, Ge S, Zhang J. The regulation of Tolllike receptor 2 by miR-143 suppresses the invasion and migration of a subset of human colorectal carcinoma cells. Mol Cancer. 2013;12:77.

153. Simmer F, Venderbosch S, Dijkstra JR, et al. MicroRNA-143 is a putative predictive factor for the response to fluoropyrimidine-based chemotherapy in patients with metastatic colorectal cancer. Oncotarget. 2015;6(26):22996-23007.

154. Iwaya T, Yokobori T, Nishida N, et al. Downregulation of miR-144 is associated with colorectal cancer progression via activation of mTOR signaling pathway. Carcinogenesis. 2012;33(12):2391-2397.

155. Pecqueux M, Liebetrau I, Werft W, et al. A comprehensive microRNA expression profile of liver and lung metastases of colorectal cancer with their corresponding host tissue and its prognostic impact on survival. Int J Mol Sci. 2016;17(10):E1755.

156. Zhou P, Sun L, Liu D, Liu C, Sun L. Long non-coding RNA lincRNA-ROR promotes the progression of colon cancer and holds prognostic value by associating with miR-145. Pathol Oncol Res. 2016;22(4):733-740.

157. Christensen LL, Tobiasen H, Holm A, et al. MiRNA-362-3p induces cell cycle arrest through targeting of E2F1, USF2 and PTPN1 and is associated with recurrence of colorectal cancer. Int $J$ Cancer. 2013;133(1):67-78.

158. Takahashi M, Cuatrecasas M, Balaguer F, et al. The clinical significance of MiR-148a as a predictive biomarker in patients with advanced colorectal cancer. PLoS One. 2012;7(10):e46684.
159. Hibino Y, Sakamoto N, Naito Y, et al. Significance of miR-148a in colorectal neoplasia: downregulation of miR-148a contributes to the carcinogenesis and cell invasion of colorectal cancer. Pathobiology. 2015;82(5):233-241.

160. Wang F, Ma YL, Zhang P, et al. SP1 mediates the link between methylation of the tumour suppressor miR-149 and outcome in colorectal cancer. J Pathol. 2013;229(1):12-24.

161. Xu K, Liu X, Mao X, et al. MicroRNA-149 suppresses colorectal cancer cell migration and invasion by directly targeting forkhead box transcription factor FOXM1. Cell Physiol Biochem. 2015;35(2): 499-515.

162. Ma Y, Zhang P, Wang F, et al. miR-150 as a potential biomarker associated with prognosis and therapeutic outcome in colorectal cancer. Gut. 2012;61(10):1447-1453.

163. Zhang L, Pickard K, Jenei V, et al. miR-153 supports colorectal cancer progression via pleiotropic effects that enhance invasion and chemotherapeutic resistance. Cancer Res. 2013;73(21):6435-6447.

164. Kai Y, Qiang C, Xinxin P, Miaomiao Z, Kuailu L. Decreased miR-154 expression and its clinical significance in human colorectal cancer. World J Surg Oncol. 2015;13:195.

165. Nishimura J, Handa R, Yamamoto H, et al. microRNA-181a is associated with poor prognosis of colorectal cancer. Oncol Rep. 2012;28(6):2221-2226.

166. Ji D, Chen Z, Li M, et al. MicroRNA-181a promotes tumor growth and liver metastasis in colorectal cancer by targeting the tumor suppressor WIF-1. Mol Cancer. 2014;13:86.

167. Pichler M, Winter E, Ress AL, et al. miR-181a is associated with poor clinical outcome in patients with colorectal cancer treated with EGFR inhibitor. J Clin Pathol. 2014;67(3):198-203.

168. Li Z, Wang H, Xu Z, Sun Y, Han J. Expression and mechanism of microRNA-181A on incidence and survival in late liver metastases of colorectal cancer. Oncol Rep. 2016;35(3):1403-1408.

169. Bovell LC, Shanmugam C, Putcha BD, et al. The prognostic value of microRNAs varies with patient race/ethnicity and stage of colorectal cancer. Clin Cancer Res. 2013;19(14):3955-3965.

170. Yamazaki N, Koga Y, Taniguchi H, et al. High expression of miR-181c as a predictive marker of recurrence in stage II colorectal cancer. Oncotarget. 2017;8(4):6970-6983.

171. Liu H, Du L, Wen Z, et al. Up-regulation of miR-182 expression in colorectal cancer tissues and its prognostic value. Int $J$ Colorectal Dis. 2013;28(5):697-703.

172. Rapti SM, Kontos CK, Papadopoulos IN, Scorilas A. Enhanced miR182 transcription is a predictor of poor overall survival in colorectal adenocarcinoma patients. Clin Chem Lab Med. 2014;52(8):1217-1227.

173. Wang S, Yang MH, Wang XY, Lin J, Ding YQ. Increased expression of miRNA-182 in colorectal carcinoma: an independent and tissue-specific prognostic factor. Int J Clin Exp Pathol. 2014;7(6): 3498-3503.

174. Zhou T, Zhang GJ, Zhou H, Xiao HX, Li Y. Overexpression of microRNA-183 in human colorectal cancer and its clinical significance. Eur J Gastroenterol Hepatol. 2014;26(2):229-233.

175. Wang ZS, Zhong M, Bian YH, et al. MicroRNA-187 inhibits tumor growth and invasion by directly targeting CD276 in colorectal cancer. Oncotarget. 2016;7(28):44266-44276.

176. Zhang F, Luo Y, Shao Z, et al. MicroRNA-187, a downstream effector of TGF $\beta$ pathway, suppresses Smad-mediated epithelial-mesenchymal transition in colorectal cancer. Cancer Lett. 2016;373(2):203-213.

177. Pichler M, Stiegelbauer V, Vychytilova-Faltejskova P, et al. Genomewide microRNA analysis identifies miR-188-3p as a novel prognostic marker and molecular factor involved in colorectal carcinogenesis. Clin Cancer Res. 2017;23(5):1323-1333.

178. Qin S, Zhu Y, Ai F, et al. MicroRNA-191 correlates with poor prognosis of colorectal carcinoma and plays multiple roles by targeting tissue inhibitor of metalloprotease 3. Neoplasma. 2014;61(1):27-34.

179. Karaayvaz M, Pal T, Song B, et al. Prognostic significance of miR215 in colon cancer. Clin Colorectal Cancer. 2011;10(4):340-347. 
180. Shan B, Chen P, Li S, Xu L, Yu H. Decreased expression of microRNA-192 correlates with tumor progression and poor prognosis in patients with colorectal cancer. Int J Clin Exp Pathol. 2017;10(1):595-602.

181. Zhang P, Ji DB, Han HB, Shi YF, Du CZ, Gu J. Downregulation of miR$193 a-5 p$ correlates with lymph node metastasis and poor prognosis in colorectal cancer. World J Gastroenterol. 2014;20(34):12241-12248.

182. Guo F, Luo Y, Mu YF, et al. miR-193b directly targets STMN1 and inhibits the malignant phenotype in colorectal cancer. Am J Cancer Res. 2016;6(11):2463-2475.

183. Zhao HJ, Ren LL, Wang ZH, et al. MiR-194 deregulation contributes to colorectal carcinogenesis via targeting AKT2 pathway. Theranostics. 2014:4(12):1193-1208.

184. Wang B, Shen ZL, Gao ZD, et al. MiR-194, commonly repressed in colorectal cancer, suppresses tumor growth by regulating the MAP4K4/ c-Jun/MDM2 signaling pathway. Cell Cycle. 2015;14(7):1046-1058.

185. Ge J, Chen Z, Li R, Lu T, Xiao G. Upregulation of microRNA-196a and microRNA-196b cooperatively correlate with aggressive progression and unfavorable prognosis in patients with colorectal cancer. Cancer Cell Int. 2014;14(1):128.

186. Boisen MK, Dehlendorff C, Linnemann D, et al. Tissue microRNAs as predictors of outcome in patients with metastatic colorectal cancer treated with first line capecitabine and oxaliplatin with or without bevacizumab. PLoS One. 2014;9(10):e109430.

187. Wang M, Wang J, Kong X, et al. MiR-198 represses tumor growth and metastasis in colorectal cancer by targeting fucosyltransferase 8 . Sci Rep. 2014;4:6145.

188. Wan D, He S, Xie B, et al. Aberrant expression of miR-199a-3p and its clinical significance in colorectal cancers. Med Oncol. 2013;30(1):378.

189. Shen ZL, Wang B, Jiang KW, et al. Downregulation of miR-199b is associated with distant metastasis in colorectal cancer via activation of SIRT1 and inhibition of CREB/KISS1 signaling. Oncotarget. 2016;7(23):35092-35105.

190. Pichler M, Ress AL, Winter E, et al. MiR-200a regulates epithelial to mesenchymal transition-related gene expression and determines prognosis in colorectal cancer patients. $\mathrm{Br} J$ Cancer. 2014;110(6):1614-1621.

191. Xi Y, Formentini A, Chien M, et al. Prognostic values of microRNAs in colorectal cancer. Biomark Insights. 2006;2:113-121.

192. Deng B, Wang B, Fang J, et al. MiRNA-203 suppresses cell proliferation, migration and invasion in colorectal cancer via targeting of EIF5A2. Sci Rep. 2016;6:28301.

193. Sümbül AT, Göğebakan B, Ergün $S$, et al. miR-204-5p expression in colorectal cancer: an autophagy-associated gene. Tumour Biol. 2014;35(12):12713-12719.

194. Yin Y, Zhang B, Wang W, et al. miR-204-5p inhibits proliferation and invasion and enhances chemotherapeutic sensitivity of colorectal cancer cells by downregulating RAB22A. Clin Cancer Res. 2014;20(23):6187-6199.

195. Sun P, Sun D, Wang X, Liu T, Ma Z, Duan L. miR-206 is an independent prognostic factor and inhibits tumor invasion and migration in colorectal cancer. Cancer Biomark. 2015;15(4):391-396.

196. Qu A, Du L, Yang Y, et al. Hypoxia-inducible MiR-210 is an independent prognostic factor and contributes to metastasis in colorectal cancer. PLoS One. 2014;9(3):e90952.

197. Sümbül AT, Göğebakan B, Bayram S, Batmacı CY, Öztuzcu S. MicroRNA 211 expression is upregulated and associated with poor prognosis in colorectal cancer: a case-control study. Tumour Biol. 2015;36(12):9703-9709.

198. Meng X, Wu J, Pan C, et al. Genetic and epigenetic down-regulation of microRNA-212 promotes colorectal tumor metastasis via dysregulation of MnSOD. Gastroenterology. 2013;145(2):426.e1-e6-436.e1-e6.

199. Chen DL, Wang ZQ, Zeng ZL, et al. Identification of microRNA-214 as a negative regulator of colorectal cancer liver metastasis by way of regulation of fibroblast growth factor receptor 1 expression. Hepatology. 2014;60(2):598-609.
200. Li S, Gao J, Gu J, Yuan J, Hua D, Shen L. MicroRNA-215 inhibits relapse of colorectal cancer patients following radical surgery. Med Oncol. 2013;30(2):549.

201. Wang B, Shen ZL, Jiang KW, et al. MicroRNA-217 functions as a prognosis predictor and inhibits colorectal cancer cell proliferation and invasion via an AEG-1 dependent mechanism. BMC Cancer. 2015; $15: 437$

202. Zhang N, Lu C, Chen L. miR-217 regulates tumor growth and apoptosis by targeting the MAPK signaling pathway in colorectal cancer. Oncol Lett. 2016;12(6):4589-4597.

203. Yu H, Gao G, Jiang L, et al. Decreased expression of miR-218 is associated with poor prognosis in patients with colorectal cancer. Int J Clin Exp Pathol. 2013;6(12):2904-2911.

204. Li PL, Zhang X, Wang LL, et al. MicroRNA-218 is a prognostic indicator in colorectal cancer and enhances 5-fluorouracil-induced apoptosis by targeting BIRC5. Carcinogenesis. 2015;36(12):1484-1493.

205. Tao K, Yang J, Guo Z, et al. Prognostic value of miR-221-3p, miR342-3p and miR-491-5p expression in colon cancer. Am J Transl Res. 2014;6(4):391-401.

206. Yuan K, Xie K, Fox J, et al. Decreased levels of miR-224 and the passenger strand of miR-221 increase MBD2, suppressing maspin and promoting colorectal tumor growth and metastasis in mice. Gastroenterology. 2013;145(4):853.e9-864.e9.

207. Cai K, Shen F, Cui JH, Yu Y, Pan HQ. Expression of miR-221 in colon cancer correlates with prognosis. Int J Clin Exp Med. 2015;8(2):2794-2798.

208. Li ZW, Yang YM, Du LT, et al. Overexpression of miR-223 correlates with tumor metastasis and poor prognosis in patients with colorectal cancer. Med Oncol. 2014;31(11):256.

209. Liao WT, Li TT, Wang ZG, et al. microRNA-224 promotes cell proliferation and tumor growth in human colorectal cancer by repressing PHLPP1 and PHLPP2. Clin Cancer Res. 2013;19(17):4662-4672.

210. Zhang GJ, Zhou H, Xiao HX, LiY, Zhou T. Up-regulation of miR-224 promotes cancer cell proliferation and invasion and predicts relapse of colorectal cancer. Cancer Cell Int. 2013;13(1):104.

211. Adamopoulos PG, Kontos CK, Rapti SM, Papadopoulos IN, Scorilas A. miR-224 overexpression is a strong and independent prognosticator of short-term relapse and poor overall survival in colorectal adenocarcinoma. Int J Oncol. 2015;46(2):849-859.

212. Ling H, Pickard K, Ivan C, et al. The clinical and biological significance of miR-224 expression in colorectal cancer metastasis. Gut. 2016;65(6):977-989.

213. He Z, Yu L, Luo S, et al. miR-296 inhibits the metastasis and epithelialmesenchymal transition of colorectal cancer by targeting S100A4 BMC Cancer. 2017;17(1):140.

214. Perez-Carbonell L, Sinicrope FA, Alberts SR, et al. MiR-320e is a novel prognostic biomarker in colorectal cancer. $B r J$ Cancer. 2015;113(1):83-90.

215. Schepeler T, Reinert JT, Ostenfeld MS, et al. Diagnostic and prognostic microRNAs in stage II colon cancer. Cancer Res. 2008;68(15): 6416-6424.

216. Wu L, Hui H, Wang LJ, Wang H, Liu QF, Han SX. MicroRNA-326 functions as a tumor suppressor in colorectal cancer by targeting the Nin one binding protein. Oncol Rep. 2015;33(5):2309-2318.

217. Sun Z, Zhang Z, Liu Z, Qiu B, Liu K, Dong G. MicroRNA-335 inhibits invasion and metastasis of colorectal cancer by targeting ZEB2. Med Oncol. 2014;31(6):982.

218. Sun K, Su G, Deng H, Dong J, Lei S, Li G. Relationship between miRNA-338-3p expression and progression and prognosis of human colorectal carcinoma. Chin Med J (Engl). 2014;127(10):1884-1890.

219. Takeyama H, Yamamoto H, Yamashita S, et al. Decreased miR-340 expression in bone marrow is associated with liver metastasis of colorectal cancer. Mol Cancer Ther. 2014;13(4):976-985.

220. Ma F, Song H, Guo B, et al. MiR-361-5p inhibits colorectal and gastric cancer growth and metastasis by targeting staphylococcal nuclease domain containing-1. Oncotarget. 2015;6(19):17404-17416. 
221. Nie J, Liu L, Zheng W, et al. MicroRNA-365, down-regulated in colon cancer, inhibits cell cycle progression and promotes apoptosis of colon cancer cells by probably targeting cyclin D1 and Bcl-2. Carcinogenesis. 2012;33(1):220-225.

222. Yamashita S, Yamamoto H, Mimori K, et al. MicroRNA-372 is associated with poor prognosis in colorectal cancer. Oncology. 2012;82(4):205-212.

223. Mo ZH, Wu XD, Li S, Fei BY, Zhang B. Expression and clinical significance of microRNA-376a in colorectal cancer. Asian Pac JCancer Prev. 2014;15(21):9523-9527.

224. Li H, Dai S, Zhen T, et al. Clinical and biological significance of miR-378a-3p and miR-378a-5p in colorectal cancer. Eur J Cancer. 2014;50(6):1207-1221.

225. Zhang GJ, Zhou H, Xiao HX, Li Y, Zhou T. MiR-378 is an independent prognostic factor and inhibits cell growth and invasion in colorectal cancer. BMC Cancer. 2014;14:109.

226. Zheng GX, Qu AL, Yang YM, Zhang X, Zhang SC, Wang CX. miR$422 \mathrm{a}$ is an independent prognostic factor and functions as a potential tumor suppressor in colorectal cancer. World J Gastroenterol. 2016;22(24):5589-5597.

227. Torres S, Garcia-Palmero I, Bartolomé RA, et al. Combined miRNA profiling and proteomics demonstrates that different miRNAs target a common set of proteins to promote colorectal cancer metastasis. J Pathol. 2017;242(1):39-51.

228. Li J, Du L, Yang Y, et al. MiR-429 is an independent prognostic factor in colorectal cancer and exerts its anti-apoptotic function by targeting SOX2. Cancer Lett. 2013;329(1):84-90.

229. Sun Y, Shen S, Tang H, et al. miR-429 identified by dynamic transcriptome analysis is a new candidate biomarker for colorectal cancer prognosis. OMICS. 2014;18(1):54-64.

230. Dong SJ, Cai XJ, Li SJ. The clinical significance of miR-429 as a predictive biomarker in colorectal cancer patients receiving 5-fluorouracil treatment. Med Sci Monit. 2016;22:3352-3361.

231. Han Y, Zhao Q, Zhou J, Shi R. miR-429 mediates tumor growth and metastasis in colorectal cancer. Am J Cancer Res. 2017;7(2): 218-233.

232. Ye YP, Wu P, Gu CC, et al. miR-450b-5p induced by oncogenic KRAS is required for colorectal cancer progression. Oncotarget. 2016;7(38):61312-61324.

233. Hata T, Mokutani Y, Takahashi H, et al. Identification of microRNA$487 \mathrm{~b}$ as a negative regulator of liver metastasis by regulation of KRAS in colorectal cancer. Int J Oncol. 2017;50(2):487-496.

234. Xu X, Chen R, Li Z, et al. MicroRNA-490-3p inhibits colorectal cancer metastasis by targeting TGF $\beta R 1$. BMC Cancer. 2015;15:1023.

235. Sun HB, Chen X, Ji H, et al. miR-494 is an independent prognostic factor and promotes cell migration and invasion in colorectal cancer by directly targeting PTEN. Int J Oncol. 2014;45(6):2486-2494.

236. Li L, Sarver AL, Khatri R, et al. Sequential expression of miR-182 and miR-503 cooperatively targets FBXW7, contributing to the malignant transformation of colon adenoma to adenocarcinoma. J Pathol. 2014;234(4):488-501.

237. Noguchi T, Toiyama Y, Kitajima T, et al. miRNA-503 promotes tumor progression and is associated with early recurrence and poor prognosis in human colorectal cancer. Oncology. 2016;90(4):221-231.

238. Zhang Y, Lin C, Liao G, et al. MicroRNA-506 suppresses tumor proliferation and metastasis in colon cancer by directly targeting the oncogene EZH2. Oncotarget. 2015;6(32):32586-32601.

239. Zhou H, Lin C, Zhang Y, et al. miR-506 enhances the sensitivity of human colorectal cancer cells to oxaliplatin by suppressing MDR1/Pgp expression. Cell Prolif. 2017;50(3):e12341.

240. Ma W, Yu Q, Jiang J, et al. miR-517a is an independent prognostic marker and contributes to cell migration and invasion in human colorectal cancer. Oncol Lett. 2016;11(4):2583-2589.

241. Ye C, Yue G, Shen Z, et al. miR-542-3p suppresses colorectal cancer progression through targeting survivin. Transl Cancer Res. 2016;5(6):817-826.
242. Yuan L, Yuan P, Yuan H, et al. miR-542-3p inhibits colorectal cancer cell proliferation, migration and invasion by targeting OTUB1. Am J Cancer Res. 2017;7(1):159-172.

243. Zhou Q, Zhu Y, Wei X, et al. MiR-590-5p inhibits colorectal cancer angiogenesis and metastasis by regulating nuclear factor $90 /$ vascular endothelial growth factor A axis. Cell Death Dis. 2016;7(10):e2413.

244. Ou C, Sun Z, Li X, et al. MiR-590-5p, a density-sensitive microRNA, inhibits tumorigenesis by targeting YAP1 in colorectal cancer. Cancer Lett. 2017;399:53-63.

245. Liu M, Zhi Q, Wang W, Zhang Q, Fang T, Ma Q. Up-regulation of miR592 correlates with tumor progression and poor prognosis in patients with colorectal cancer. Biomed Pharmacother. 2015;69:214-220.

246. Shi F, Li R, Guo P. Expression and prognostic value of miR-610 in patients with colorectal cancer. Biomed Res. 2017;28(3):1321-1324.

247. Rasmussen MH, Jensen NF, Tarpgaard LS, et al. High expression of microRNA-625-3p is associated with poor response to first-line oxaliplatin based treatment of metastatic colorectal cancer. Mol Oncol. 2013;7(3):637-646.

248. Lou X, Qi X, Zhang Y, Long H, Yang J. Decreased expression of microRNA-625 is associated with tumor metastasis and poor prognosis in patients. $J$ Surg Oncol. 2013;108(4):230-235.

249. Chu D, Zheng J, Li J, et al. MicroRNA-630 is a prognostic marker for patients with colorectal cancer. Tumour Biol. 2014;35(10):9787-9792.

250. Zhang J, Fei B, Wang Q, et al. MicroRNA-638 inhibits cell proliferation, invasion and regulates cell cycle by targeting tetraspanin 1 in human colorectal carcinoma. Oncotarget. 2014;5(23):12083-12096.

251. Wang X, Kuang Y, Shen X, et al. Evaluation of miR-720 prognostic significance in patients with colorectal cancer. Tumour Biol. 2015;36(2):719-727.

252. Zhang T, Cai X, Li Q, et al. Hsa-miR-875-5p exerts tumor suppressor function through down-regulation of EGFR in colorectal carcinoma (CRC). Oncotarget. 2016;7(27):42225-42240.

253. Liu DR, Guan QL, Gao MT, Jiang L, Kang HX. miR-1260b is a potential prognostic biomarker in colorectal cancer. Med Sci Monit. 2016;22:2417-2423.

254. Gopalan V, Pillai S, Ebrahimi F, et al. Regulation of microRNA-1288 in colorectal cancer: altered expression and its clinicopathological. Mol Carcinog. 2014;53(Suppl 1):E36-E44.

255. Ju HQ, Lu YX, Chen DL, et al. Redox regulation of stem-like cells through the CD44v-xCT Axis in colorectal cancer: mechanisms and therapeutic implications. Theranostics. 2016;6(8):1160-1175.

256. Hu Y, Yi B, He S, et al. Clinical significance of miR-1826 as a novel prognostic biomarker in colorectal cancer. Anticancer Agents Med Chem. 2016;16(9):1109-1116.

257. Yu FY, Tu Y, Deng Y, et al. MiR-4500 is epigenetically downregulated in colorectal cancer and functions as a novel tumor suppressor by regulating HMGA2. Cancer Biol Ther. 2016;17(11):1149-1157.

258. Zhao S, Sun H, Jiang W, et al. miR-4775 promotes colorectal cancer invasion and metastasis via the Smad7/TGF $\beta$-mediated epithelial to mesenchymal transition. Mol Cancer. 2017;16(1):12.

259. Jemal A, Siegel R, Xu J, Ward E. Cancer statistics, 2010. CA Cancer J Clin. 2010;60(5):277-300.

260. Valeri N, Croce CM, Fabbri M. Pathogenetic and clinical relevance of microRNAs in colorectal cancer. Cancer Genomics Proteomics. 2009;6(4):195-204.

261. Forman JJ, Legesse-Miller A, Coller HA. A search for conserved sequences in coding regions reveals that the let- 7 microRNA targets Dicer within its coding sequence. Proc Natl Acad Sci U SA. 2008;105(39):14879-14884.

262. Lagos-Quintana M, Rauhut R, Lendeckel W, Tuschl T. Identification of novel genes coding for small expressed RNAs. Science. 2001;294(5543):853-858.

263. Lau NC, Lim LP, Weinstein EG, Bartel DP. An abundant class of tiny RNAs with probable regulatory roles in Caenorhabditis elegans. Science. 2001;294(5543):858-862.

264. Lee RC, Ambros V. An extensive class of small RNAs in Caenorhabditis elegans. Science. 2001;294(5543):862-864. 
265. Tierney JF, Stewart LA, Ghersi D, Burdett S, Sydes MR. Practical methods for incorporating summary time-to-event data into metaanalysis. Trials. 2007;8:16.

266. Lin JK, Chang SC, Yang YC, Li AF. Loss of heterozygosity and DNA aneuploidy in colorectal adenocarcinoma. Ann Surg Oncol. 2003;10(9):1086-1094.

267. Leary RJ, Lin JC, Cummins J, et al. Integrated analysis of homozygous deletions, focal amplifications, and sequence alterations in breast and colorectal cancers. Proc Natl Acad Sci U S A 2008;105(42):16224-16229.
268. Guastadisegni C, Colafranceschi M, Ottini L, Dogliotti E. Microsatellite instability as a marker of prognosis and response to therapy: a meta-analysis of colorectal cancer survival data. Eur J Cancer. 2010;46(15):2788-2798.

269. Ogino S, Chan AT, Fuchs CS, Giovannucci E. Molecular pathological epidemiology of colorectal neoplasia: an emerging transdisciplinary and interdisciplinary field. Gut. 2011;60(3):397-411.

270. Ogino S, Nishihara R, van der Weele TJ, et al. The role of molecular pathological epidemiology in the study of neoplastic and nonneoplastic diseases in the era of precision medicine. Epidemiology. 2016;27(4):602-611.
Cancer Management and Research

\section{Publish your work in this journal}

Cancer Management and Research is an international, peer-reviewed open access journal focusing on cancer research and the optimal use of preventative and integrated treatment interventions to achieve improved outcomes, enhanced survival and quality of life for the cancer patient The manuscript management system is completely online and includes

\section{Dovepress}

a very quick and fair peer-review system, which is all easy to use. Visit http://www.dovepress.com/testimonials.php to read real quotes from published authors. 